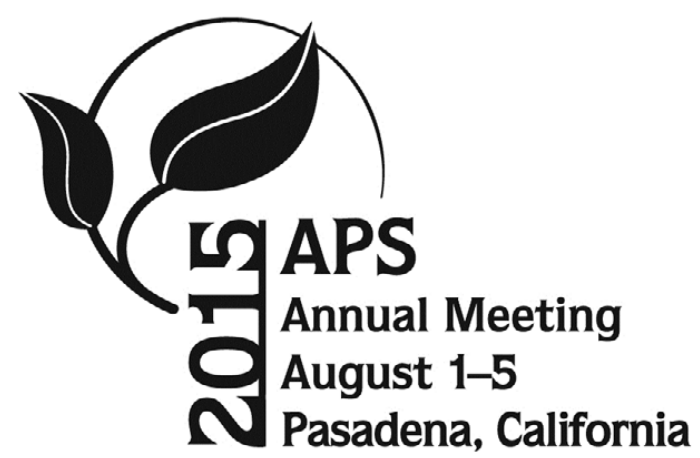

\title{
2015 APS Annual Meeting Abstracts of Special Session Presentations
}

\section{Biology of Pathogens}

\section{Advances in Gene Silencing}

Antiviral silencing in plants and animals

S. W. DING (1)

(1) University of California, Riverside, CA, U.S.A.

Phytopathology 105(Suppl. 4):S4.161

Plant and animal hosts process virus-specific dsRNA into siRNAs (vsiRNAs) to confer only specific virus resistance. Accordingly, antiviral silencing is not expected to play a role in the broad-spectrum plant systemic acquired resistance. We have recently described a novel class of Arabidopsis endogenous siRNAs induced after infection by Cucumber mosaic virus (CMV) or Turnip mosaic virus (TuMV). These virus-activated siRNAs (vasiRNAs) are predominantly 21 nucleotides long, are mapped to the exon regions of $>1,000$ host genes and rRNA, and represent $20 \%$ of the total endogenous 21 -nt RNAs sequenced from the infected plants. Production of vasiRNAs is inhibited by CMV silencing suppressor $2 b$, but not by TuMV HC-Pro. Unlike the known plant endo-siRNAs characterized to date, vasiRNAs resemble secondary vsiRNAs by requiring DCL4 and RDR1 for biogenesis. However, loss of XRN4/EIN5 enhances vasiRNA biogenesis and virus resistance independently of vsiRNAs. We show that vasiRNAs direct widespread silencing of the targeted host genes in a pathway involving DCL4, AGO2 and RDR1. Notably, vasiRNAs induced by CMV and TuMV target overlapping sets of host genes in biotic and abiotic responses. We propose that antiviral silencing activates broad-spectrum antiviral activity via widespread silencing of host genes directed by vasiRNAs in addition to specific antiviral defense by vsiRNAs.

Tomato bushy stunt virus as a model system to study antiviral RNA silencing

H. B. SCHOLTHOF (1)

(1) Texas A\&M University, College Station, TX, U.S.A.

Phytopathology 105(Suppl. 4):S4.161

Antiviral RNA silencing is a process that specifically recognizes and degrades viral RNA, and as a countermeasure many viruses evolved suppressors that block this RNA silencing defense. One of the best-characterized suppressors is the Tomato bushy stunt virus (TBSV) encoded P19 that interferes with RNA silencing in plants and RNAi in many organisms by sequestering siRNAs. A

The abstracts are published as submitted. They were formatted but not edited at the APS headquarters office.

http://dx.doi.org/10.1094/PHYTO-105-11-S4.161

(C) 2015 The American Phytopathological Society likely primary mechanistic role for siRNA binding by P19 during infection of plants with TBSV is to avoid programming of an ARGONAUTE (AGO) in the RNA-induced silencing complex (RISC) with viral siRNAs. Using several chromatography procedures with extracts from plants infected with different TBSV variants, direct biochemical evidence was obtained for virus siRNA sequestration by $\mathrm{P} 19$, and for the programming of a bona fide virus sequencespecific RISC in absence of P19. Furthermore, VIGS and hairpin technology in combination with new GFP-expressing TBSV vectors provided evidence that $\mathrm{AGO} 2$ is important for antiviral silencing against TBSV in Nicotiana benthamiana. Silencing against TBSV is especially strong in mature roots when compared to leaves, which may be related to the findings that the level of $\mathrm{AGO} 2$ expression is age- and tissue-dependent and increases upon infection. AGO2 may also play a role in controlling susceptibility to select viruses other than TBSV.

Diverse silencing suppressors and RNAi interactions among members of the Closteroviridae

B. FALK (1), W. Qiao (1), C. Rosa (2)

(1) Department of Plant Pathology, University of California, Davis, CA, U.S.A.; (2) Department of Plant Pathology, Pennsylvania State University, University Park, PA, U.S.A.

Phytopathology 105(Suppl. 4):S4.161

Viruses in the family Closteroviridae are widespread and important plant viruses. Most members of the family are phloem-limited within their plant hosts, and are obligately transmitted to plants by specific phloem-feeding insect vectors. Furthermore, these viruses have the largest and most complex virions and genomes of all the currently recognized +ssRNA plant viruses. Within their complex genomes different closteroviruses have been shown to encode various proteins that can suppress RNA silencing. For example Citrus tristeza virus (CTV) encodes for 3 proteins that interfere with distinct steps in the RNAi pathway, while Lettuce infectious yellows virus (LIYV), which must encode for a silencing suppressor but conventional silencing suppressor assays so far have failed to demonstrate activity. In addition to the complexities of their silencing suppressor diversity, closteroviruses have proven to be difficult targets for RNAi-based virus resistance strategies. We have recently engineered immunity to LIYV and Cucurbit yellow stunting disorder virus (CYSDV) by targeting the RNA 1 L-Pro region. Despite their diversity and abundance of encoded silencing suppressors, our data show that RNAi-based immunity can be achieved against at least some members of this family of viruses.

A reexamination of the relationship between RNA silencing and cross protection

X. Zhang (1), F. QU (1)

(1) The Ohio State University, Wooster, OH, U.S.A.

Phytopathology 105(Suppl. 4):S4.161 
Plants infected with a multi-variant virus population often retain just a few dominant variants whose identities differ from plant to plant in a stochastic manner. To elucidate the underlying bottlenecking mechanism, we analyzed the fate of a nine-variant population of turnip crinkle virus (TCV) in 20 host plants by assessing the relative abundance of each of the variants in both inoculated leaves (ILs) and upper uninoculated leaves (ULs) of every plant. We found that while all variants accumulated to similar levels in ILs, one to two random variants dominated the ULs. Importantly, this stochastic dominance persisted in RNA silencing-defective plants, ruling out a prominent role for RNA silencing in this process. Furthermore, our sequential inoculation experiments suggest that variants dominating ULs of a given plant are likely the ones that reached the ULs the earliest. Finally, we show that ULs were the sites of repression as ULs pre-infected by one TCV variant became highly resistant to secondary inoculations of a different TCV variant. Based on these results, we propose that spatially random distribution of variant foci on ILs endows precedent systemic movement to different variants in different plants. The early moving variants then colonize ULs, and repress the late arrivers through superinfection exclusion. These findings establish a mechanistic link between viral population bottlenecking, superinfection exclusion, and cross protection.

A novel chemopreventive strategy using tumor suppressor microRNAs produced in edible plants

V. VANCE (1), S. Mlotshwa (1), G. J. Pruss (1), J. L. MacArthur (1), C. Davis (1), L. Hofseth (1), M. M. Pena (1)
(1) University of South Carolina, Columbia, SC, U.S.A Phytopathology 105(Suppl. 4):S4.162

The idea that small RNAs ingested from plant-based foods could have biological effects in humans and other mammals is currently an issue of considerable interest. It has long been known that ingested RNA from food sources is taken up by the digestive system in nematodes and insects and can control the expression of genes in those organisms. A recent report has raised the interesting possibility that a similar phenomenon occurs in humans and other mammals. This work has generated excitement because it raises the possibility of bioengineering edible plants to produce therapeutic miRNAs that could then be delivered to affected tissues by ingestion. However, it has also generated controversy, and several groups have challenged the finding. We addressed this controversy in an experiment designed to both detect a therapeutic effect of ingested miRNAs and to demonstrate their uptake in a mouse model for colon cancer. Our results indicate that tumor suppressor miRNAs designed to mimic small RNAs produced in plants were taken up by the mouse digestive tract upon ingestion and were functional as evidenced by reduction in tumor burden. Our results support the original finding that endogenous plant miRNAs are taken up by the mammalian digestive tract and function to target mammalian genes, raising the intriguing prospect of using edible plants engineered to produce mammalian tumor suppressor miRNAs as an effective, nontoxic, and inexpensive chemopreventive strategy in humans.

\section{Life Beyond the Plant: Bacterial Wars}

Biochemical and structural basis of toxicity and immunity in contactdependent growth inhibition (CDI) systems

D. A. LOW (1), Z. Ruhe (1), C. Hayes (1), S. Koskiniemi (2), C. Goulding (3), S. Poole (1)

(1) University of California, Santa Barbara, CA, U.S.A.; (2) Uppsala University, Uppsala, Sweden; (3) University of California, Irvine, CA, U.S.A. Phytopathology 105(Suppl. 4):S4.162

Many bacterial pathogens, including some that attack plants, express one or more systems that block the growth of neighboring cells that are recognized as "non-self". Systems designated as "CDI" (contact-dependent growth inhibition) inhibit the growth of neighboring cells via expression of large extended beta-helical structures, called CdiA, on their surfaces. CdiA proteins recognize specific receptors on susceptible target bacteria. CdiA(EC93) from E. coli EC93 uses the highly conserved outer-membrane protein, BamA, as its receptor, but other CdiA proteins bind different receptor molecules. Upon binding its receptor, CdiA delivers a C-terminal toxin domain (CdiA-CT) into the target bacterium. Many CDI toxins are nucleases, and thus must traverse both the outer- and inner membrane to gain access to their target substrates. $\mathrm{CDI}+$ cells protect themselves from toxin activity by producing a CdiI immunity protein encoded immediately downstream of $c$ diA. CdiI binds to the CdiA-CT toxin and neutralizes its activity. Each CdiI immunity protein binds specifically to its cognate CdiA toxin, enabling self-recognition. Further recognition occurs at the receptor binding level. Polymorphic extracellular loops of BamA serve as binding sites for CdiA(EC93). This restricts this E. coli CDI system to delivering toxin only to other E. coli cells that express BamA with appropriate loop sequences.

Molecular mechanisms of the Agrobacterium Type VI DNase effector secretion and antibacterial activity during plant colonization

D. Bondge (1), J. S. Lin (1), L. S. Ma (1), E. M. LAI (1)

(1) Institute of Plant and Microbial Biology, Academia Sinica, Taipei, Taiwan Phytopathology 105(Suppl. 4):S4.162

About a third of Gram-negative bacteria encode one or multiple type VI secretion systems (T6SS) that function to inject effectors/toxins into eukaryotic or prokaryotic cells to benefit their survival and fitness. Structural and functional studies revealed that T6SS machine resembles bacteriophage tail-like structure with valine glycine repeat $\mathrm{G}$ (VgrG) likely acting as a spike protein to pierce the host cell membrane for effector delivery. We study the secretion mechanisms and effector functions of T6SS in Agrobacterium tumefaciens, a plant pathogenic bacterium causing crown gall disease in a wide range of plants. A. tumefaciens T6SS produces three toxins, namely a peptidoglycan targeting protein Tae and two nucleic acid targeting proteins Tde1 and Tde2, which confer T6SS-dependent interbacterial competitive advantage to $A$. tumefaciens inside the host plant. Further studies revealed that two VgrG paralogs in A. tumefaciens, namely VgrG1 and VgrG2, specifically control the secretion and in-planta bacterial competition activity of Tde1 and Tde2, respectively. By deletion and domain swapping, we revealed that the variable $\mathrm{C}$-terminal region of $\mathrm{VgrGs}$ is responsible for the Tde secretion and/or bacterial competition specificity. The molecular determinants responsible for Tde secretion specificity and underlying mechanisms will be presented and discussed.

Identification and characacterization of interstrain chemical weapons in the Ralstonia solanacearum species complex

A. I. HUERTA (1), F. Ailloud (2), C. Allen (1)

(1) University of Wisconsin - Madison, Madison, WI, U.S.A.; (2) CIRAD, UMR Peuplements Végétaux et Bioagresseurs en Milieu Tropical, CIRADUniversité de la Réunion, Pôle de Protection des Plantes, Saint Pierre, La Réunion, France; ANSES Plant Health Laboratory, Saint Pierre, La Réunion, France

Phytopathology 105(Suppl. 4):S4.162

The globally distributed Ralstonia solanacearum species complex includes thousands of genetically distinct strains. Most are soilborne and many can infect tomato plants, but multiple strains have never been isolated from a single plant in the field. Pairwise inoculations of tomato plants demonstrated large differences in competitive fitness among three phylogenetically distinct $R$. solanacearum strains. North American strain K60 outcompeted Asian tropical lowland strain GMI1000 and the South American Race 3 highland strain UW551. Similar relative competitive fitness patterns were observed when strains were cultured together in broth, suggesting that this pathogen deploys chemical weapons against related strains. Reciprocal overlay plate inhibition assays using cell-free supernatants from 15 diverse $R$. solanacearum strains revealed that most strains produce multiple proteinaceous interstrain inhibitors. Screening a strain K60 mutant library for loss of inhibitory ability identified a cluster of Rhs domain genes, which often encode cell surface or secreted toxins. These mutants could not inhibit growth of GMI1000 or UW551 on plates and also could no longer outcompete UW551 in tomato stems. Nearly all sequenced $R$. solanacearum genomes contain multiple Rhs genes, suggesting that Rhs-type bacteriocins may act generally in competitive fitness and exclusion of this major pathogen. 


\section{Mycotoxins: From Production, Secretion, and Detection to Effects on Plants and Mammals}

The Cross-kingdom languages of Aspergillus flavus

N. KELLER (1), J. Spraker (1), G. Fischer (1)

(1) University of Wisconsin, Madison, WI, U.S.A.

Phytopathology 105(Suppl. 4):S4.163

Aspergillus flavus is notorious for its ability to contaminate several seed crops with aflatoxin, the most carcinogenic mycotoxin known to humankind. The ability of the fungus to grow and synthesize aflatoxin is dependent on its interactions with both exogenous and endogenous signaling molecules. Here we describe two cross-kingdom communication networks, one an oxylipin signaling pathway between host seed and A. flavus and one showing small molecule driven communications between $A$. flavus and the bacterium Ralstonia solanacearum. In the former, we present data supporting a shared oxylipin currency that drives a quorum like developmental program in $A$. flavus and impacts host ingress and aflatoxin synthesis. In the latter, we discuss a newly identified $R$. solanacearum diffusible signal that not only induces chlamydospore formation in A. flavus but is also associated with bacterial ingress into the chlamydospore.

Cellular localization of mycotoxin synthesis and mechanisms for export M. Boenisch (1), B. Yordem (2), K. Broz (2), H. C. KISTLER (2)

(1) University of Minnesota, St. Paul, MN, U.S.A.; (2) USDA, University of Minnesota, St. Paul, MN, U.S.A.

Phytopathology 105(Suppl. 4):S4.163

Fusarium graminearum causes scab on wheat and contaminates grain with trichothecene mycotoxins making it unfit for human consumption. Little is known about cellular and subcellular changes that occur during toxigenesis that may facilitate trichothecene synthesis and export. Enzymes catalyzing early and late steps in trichothecene biosynthesis, HMG CoA reductase (Hmrlp), trichodiene oxygenase (Tri4p), and calonectrin oxygenase (Trilp), localize to spherical subcellular structures called "toxisomes" under toxin inducing conditions such as during infection of wheat. Toxisomes co-localize with the endoplasmic reticulum (ER). ER organization shifts from being highly reticulate to being tubular and having pronounced perinuclear position upon toxin induction. Strict co-localization of Hmrlp, Tri4p, and Trilp suggest that the enzymes may be a multi-enzyme complex, a hypothesis supported by fluorescence resonance energy transfer between the fluorescently tagged proteins. Unlike the ER-localized biosynthetic enzymes, the export of trichothecenes is linked to endosomes. The trichothecene transporter Tri12p::GFP localizes to small $(1 \mu \mathrm{m})$ motile vesicles, vacuoles and the plasma membrane, based on co-localization with fluorescent dyes CMAC and FM4-64. Motile Tri12p vesicles fuse with the vacuole or plasma membrane, suggesting that vesicular transport plays a role in export of trichothecenes. These results suggest a role for vesicular trafficking and exocytosis in toxin export.

Using immunology and LC-MS/MS to simultaneously detect multiple mycotoxins in food and feed

P. LI (1), Z. Zhang (1), Q. Zhang (1)

(1) Oil Crops Research Institute of CAAS, Wuhan, China

Phytopathology 105(Suppl. 4):S4.163

Multiple mycotoxins with strong carcinogenesis and toxicity are fatal threats in food and feed safety, and require highly sensitive and high-throughput detections greatly. Rapid immunoassay and arbitration detection methods play a critical role on two sides of one coin. For rapid tests, a series of high specific and high affinity monoclonal antibody, recombinant antibody, and nanobody against AFB1, OTA, and ZEA, etc, were developed as the key recognition reagents. Based on these specific antibodies, simultaneous detection for multiplexed mycotoxins was studied by using the Au (or Europium)-based lateral flow strip and non-fouling antigen microarray. The LOD was lowered to $\mathrm{pg} \mathrm{mL} \mathrm{m}^{-1}$ level $\left(0.3 \mathrm{pg} \mathrm{mL}^{-1}\right)$ in food and feed samples. On the other hand, simultaneous arbitration detection method based on LC-MS/MS was investigated. Either multiple immunoaffinity column or SPE was used in the sample extraction. The internal standard allowed precise determination of mycotoxins regardless of matrices. Multiplexed mycotoxins (AFB1, B2, G1, G2, OTA, ZEA, and T-2 toxin) were successfully identified by using a novel multi-immunoaffinity column in a single run. Furthermore, a promising proposal was suggested to achieve the rapid, sensitive, ultra high-throughput detection of 96-384 contaminants in food and feed, including biotoxins, pesticides, veterinary drugs, etc., based on immunochemiluminescence biosensors using Hadamard transformation imaging (iHT).

Feeding issues in hogs, cattle and poultry from diseased and mycotoxin contaminated grain

B. RICHERT (1)

(1) Purdue University, West Lafayette, IN, U.S.A.

Phytopathology 105(Suppl. 4):S4.163

Mycotoxin contamination of feed ingredients have considerable economic costs including the cost of reduced animal performance and health, feeding mitigation practices, and potentially contaminated foods of animal origin. Globally much research has sought to find methods to overcome these mycotoxins issues for livestock and poultry feeding. Currently, the best procedure is to minimize animal exposure to mycotoxins by sourcing grains and feedstuffs that are low in mycotoxins. At times this may be difficult to accomplish and grain by-products, such as DDGS, actually increase the mycotoxins concentrations up to $3 \mathrm{X}$. Mycotoxins in very small concentrations (parts per billion) can causing reduced growth rate and feed efficiency, abortions and conception difficulties, and reduced immune function. One of the most common approaches for the prevention of aflatoxicosis in livestock is the addition of adsorbents that bind aflatoxin in the GIT and are capable of reducing its biological activity in the animal. However, binding is not as effect for other mycotoxins. Substances used as mycotoxin binders are indigestible adsorbent materials such as silicates, activated carbons, complex carbohydrates and others. Currently, no adsorbent product is approved by the FDA for the prevention or treatment of aflatoxicoses or mycotoxicoses. The latest research is focusing on enzyme technologies to deactivate mycotoxins, reducing their biological activity for livestock and poultry.

\section{Human health effects of mycotoxins: Advances and updates}

J. S. WANG (1)

(1) University of Georgia, Athens, GA, U.S.A

Phytopathology 105(Suppl. 4):S4.163

Mycotoxins are toxic fungal metabolites and several groups of these toxins, such as aflatoxins, fumonisins, certain tricothecenes, ochratoxins, and zearalenone are ubiquitous foodborne toxicants and have been implicated either in highly lethal episodic outbreaks of mycotoxicoses in exposed animals and human populations or chronic human diseases, such as cancers. Importantly, global climate changes in past decades have made expansion of the "growth hot zone" for these mycotoxin-producing fungi to 10 degrees further in both north and south latitudes, which cover most part of world, resulting increase in exposure to mycotoxins in animals and human populations in Europe and North America in recent years. Current focuses on mycotoxin and human health research include: 1) reproductive and developmental toxic effects of mycotoxins in birth defects and growth inhibition, such as stunting in children; 2) immunotoxic effects of mycotoxins and their roles in human carcinogenesis and infectious diseases; 3 ) adverse health effects of co-exposure to multiple mycotoxins, especially with the synergistic toxic effects found in various animal models and human populations; 4) molecular mechanisms of multiple mycotoxins exposureinduced adverse health outcomes with special emphasis on interactions of genetic and epigenetic modifications, and 5) development of new intervention and prevention strategies for mitigation of human mycotoxins exposure and their adverse health effects.

\section{Nematology: From Microbiomes to Management}

Soil microbiome potential for management of phytoparasitic nematodes A. CIANCIO (1), M. Colagiero (1), I. Pentimone (1), L. Rosso (1) (1) CNR, Istituto per la Protezione Sostenibile delle Piante - IPSP, Bari, Italy Phytopathology 105(Suppl. 4):S4.163
Soil microbiome has a significant impact on phytoparasitic nematodes. However, given the number of species present in soil, its role is difficult to study with traditional approaches. Advanced technologies, i.e. Next Generation Sequencing (NGS), allow the identification and quantitative determination of almost all species in a sample, enlarging our view about their rhizosphere effects. Metagenomic studies showed that microbial species may reach $10^{4}$ or more taxonomic units in a few $\mathrm{g}$ of soil. Comparing these 
numbers with the nematode bacterial antagonists known we can infer that biocontrol studies have yet a large space to explore. The activity of soil microbiome on nematodes can show suppressivity, but active species may remain undetected or unknown. To measure suppressive potential, a study was carried out with soil from a carnation crop with patchy Meloidogyne spp. infestations. After 4-years continuous croppings on tomato, $40 \%$ of pots showed nematode extinction, suggesting suppression or biological containment on a long time scale. In vitro NGS studies are needed to identify the role of a specific microbial component. The endophytic and nematode parasitic fungus Pochonia chlamydosporia showed differential expression of resistance and defensive genes in colonized tomato roots. Depending on the experimental approach, NGS studies provide a wide basis to understand the impact of soil microbiome and how phytonematode attacks may be balanced through management.

Comparative nematode neuroanatomy: Wandering through worm wiring N. SCHROEDER (1), Z. Han (1)

(1) University of Illinois Urbana-Champaign, Urbana, IL, U.S.A.

Phytopathology 105(Suppl. 4):S4.164

As animals, plant-parasitic nematodes are unique among the organisms typically studied within the field of plant pathology. All nematodes have a nervous system which regulates behavior. Nervous system disruption of parasitic nematodes is a current control strategy through compounds acting as cholinesterase inhibitors and ion channel agonists. Much of our understanding of nematode neurobiology is influenced by studies in two nematodes: the freeliving species Caenorhabditis elegans and the mammalian gastrointestinal parasite Ascaris suum. C. elegans and A. suum are remarkably dissimilar species with surprisingly similar neuroanatomies. From these and a handful of other studies it is often assumed that nematode neuroanatomy is highly conserved. However, a close examination of previous literature suggests that nervous system evolution in nematodes is more dynamic than previously thought. We have expanded on these previous data by performing a comparative analysis of nematodes from several clades to the wellcharacterized neuroanatomy of $C$. elegans. Using a combination of fluorescent nuclear staining and differential interference contrast microscopy, we found previously undescribed variation in the total number of putative neurons and their timing of development. Comparative dye-filling experiments also suggest variation in the structure and/or accessibility of sensory neurons among nematode species.

\section{Multitrophic interactions and the chemical ecology of nematodes}

J. G. ALI (1)

(1) Michigan State University, Entomology Department, East Lansing, MI, U.S.A.

Phytopathology 105(Suppl. 4):S4.164

Plants can influence the behavior of and modify community composition of soil dwelling organisms through the exudation of organic molecules. Given the chemical complexity of the soil matrix, soil-dwelling organisms have evolved the ability to detect and respond to these cues for successful foraging. A key question is how specific these responses are and how they may evolve. Soil nematodes are a group of diverse functional and taxonomic types, which may reveal a variety of responses. Herbivore-induced volatile emissions benefit plant hosts by recruiting natural enemies of herbivorous insects. Such tritrophic interactions have been examined thoroughly in aboveground terrestrial environments. Recently, similar signals have been described in the subterranean environment, which may be of equal importance for indirect plant defense. Our work has shown that plant roots of citrus defend themselves against root herbivores by releasing an herbivore-induced plant volatile (HIPV), pregeijerene (1,5-dimethylcyclodeca-1,5,7-triene), that attracts naturally occurring entomopathogenic nematodes (EPNs) to larvae when applied in the field. However, the soil community is complex, containing a diversity of interspecies relationships that modulate food web assemblages. In a series of experiments we examine the specificity of this HIPV in the complex nematode community, including beneficial entomopathogenic nematodes, plant-parasitic nematodes, as well as, hyperparasitic nematodes and nematophagous fungi. We provide the first evidence showing subterranean HIPVs behave much the same as those aboveground, attracting not only parasitoids, but also hyperparasites and other food web members.

Breeding for nematode resistance: New phenotypic tools for a new era S. COOPER (1), A. Coburn (1), M. Easter (1), J. Yates (1)

(1) Monsanto Company, Chesterfield, MO, U.S.A.

Phytopathology 105(Suppl. 4):S4.164

The soybean cyst nematode (SCN), Heterodera glycines Ichinohe, is the most damaging pest of soybeans in the US. Losses from SCN in have been estimated at $\$ 1$ billion annually in the US alone. The primary plant protection method is planting SCN resistance varieties. Over $85 \%$ of soybean varieties on the marketplace have a form natural resistance to SCN. Although the underlying techniques for screening soybean lines for resistance has not changed much overtime, advances in molecular markers and automation can streamline and optimize the process. Monsanto has reduced the number of data point required to characterize the pipeline, increased the number of pathotypes utilized to characterize the pipeline and reduced the cost of an individual data point through the use of molecular markers and innovations within the phenotyping screen. In this session, we will discuss utilization of molecular markers to prioritize germplasm for screening and explore equipment to optimize the SCN phenotyping.

Advances in science to meet real world crop production needs

D. SKLARCZYK (1)

(1) Sklarczyk Seed Farm LLC, Johannesburg, MI, U.S.A.

Phytopathology 105(Suppl. 4):S4.164

Sklarczyk Seed Farm (SSF), Johannesburg MI, focuses on hard work and new ideas. The farm was purchased by Dons's parents in1942. In the 1980's, SSF adopted tissue culture to reduce latent virus and symptomless bacteria in seed potatoes. In the 1990's, SSF switched from artificial media to hydroponics. SSF produced more than 5,000,000 mini tubers in 2014. These are planted in over 250A in the USA, Canada, Chile, Vietnam, Thailand, Egypt, Mexico, Egypt and Brazil. What started as an idea from advances in science has global impact. SSF interacts with the MI Seed Potato Assoc., MI Potato Industry Com. and National Potato Council. These connect researchers and growers for the best research possible. Accountability is front and center. SSF has had input on proposals for NIFA, ARS and SARE. This facilitates Connecting Advances in Science to Meet Real World Crop Production Needs. Crop failures are prevented by connecting researchers and growers. With global trade, risk of exotic pathogens is not science fiction. Today soil health is being addressed in cooperation with academia and government. Where must we go to keep up with future needs? Ideas and concepts from human research and overall human ingenuity will be used. Partners will widen to areas not currently involved. Concepts like these unite researches and farmers, looking to the future and exploring ideas outside the traditional box.

\section{Phytophthora tentaculata, A Newly Introduced Nursery Pathogen and How Clean Stock Production Systems Can Limit Disease Spread}

Phytophthora tentaculata, a new Phytophthora species in the United States affecting California native plants, grown in nurseries

S. ROONEY-LATHAM (1), C. L. Blomquist (1), Y. Y. Guo (1), M. C. Soriano (1), K. L. Kosta (1), T. J. Swiecki (2), E. A. Bernhardt (2), S. J. Frankel (3)

(1) California Department of Food and Agriculture, Sacramento, CA, U.S.A.; (2) Phytosphere Research, Vacaville, CA, U.S.A.; (3) USDA Forest Service, Pacific Southwest Research Station, Albany, CA, U.S.A.

Phytopathology 105(Suppl. 4):S4.164

Phytophthora tentaculata is a homothallic species that causes a root and crown disease of nursery plants in Europe and China. In 2012, P. tentaculata was detected for the first time in North America on the roots and crowns of declining sticky monkey flower plants (Diplacus aurantiacus) in a Monterey Co., CA native plant nursery. In 2014, P. tentaculata was detected on toyon (Heteromeles arbutifolia) and sticky monkey flower plants that were outplanted in a restoration site in CA. These plants originated in a nursery in Placer Co. where coffeeberry plants (Frangula californica) were also found to be infected. In response to the detections and concerns of spreading exotic Phytophthora species by outplanting native plants, the CDFA lab tested more than 800 samples in 2014 for Phytophthora spp. Samples were collected from native plant nurseries and wildlands and tested by immunoassay, culturing, baiting and PCR using Phytophthora-specific primers. In addition to $P$. tentaculata, at least 18 other species of Phytophthora were detected from the roots of symptomatic plants. To date, $P$. tentaculata has been detected in 5 native plant nurseries and 4 restoration sites in $\mathrm{CA}$ but has not yet been detected in native species growing in undisturbed sites or plants adjacent to outplanted, infected stock. Restoration nurseries provide planting stock for 
environmental mitigation and the inadvertent spread of Phytophthora species could have long-term environmental and economic impacts.

Phytophthora tentaculata and other Phytophthora species introduced into California native habitats via nursery stock

T. J. SWIECKI (1), E. Bernhardt (1), S. Rooney Latham (2), C. Blomquist (2), S. J. Frankel (3), K. Kosta (2)

(1) Phytosphere Research, Vacaville, CA, U.S.A.; (2) California Department of Food and Agriculture, Sacramento, CA, U.S.A.; (3) USDA Forest Service, Pacific Southwest Research Station, Albany, CA, U.S.A.

Phytopathology 105(Suppl. 4):S4.165

The second detection of Phytophthora tentaculata in the US was in recentlyplanted toyon (Heteromeles arbutifolia) nursery stock at a habitat restoration site in Alameda Co., California. Subsequent sampling indicated that $P$. tentaculata was introduced into at least one other site via planting stock from the same nursery. At this second site, P. tentaculata was recovered from Diplacus auriantiacus planted in two successive years, showing that the pathogen could persist in the field from year to year and that symptom expression can be delayed. $P$. tentaculata was also introduced via material from a different nursery into at least one restoration site in Monterey Co. Recent sampling shows that Phytophthora spp. have been common in California native plant and restoration nurseries and that Phytophthorainfested plant material is commonly planted into native habitats. In addition to $P$. tentaculata, we have recovered $P$. cactorum, $P$. cambivora, $P$. cryptogea, $P$. inundata, $P$. megasperma, $P$. nicotianae, $P$. niederhauserii, $P$. pini, and $P$. quercetorum from stock planted in restoration sites. Restoration practitioners have been unfamiliar with Phytophthora root rots and expect mortality in new plantings. Consequently, planting of diseased stock has gone unrecognized. Escape of exotic Phytophthora spp. into native vegetation poses a threat to a wide variety of common and rare species. Planting of infested material directly into habitat can result in permanent habitat degradation.

Phytophthora tentaculata Prioritized Host range study for restoration nursery producers: CA native plants and woody perennials

K. SUSLOW (1), W. Schweigkofler (2), K. Kosta (3), T. Pastalka (2), S. Sharma (2)

(1) National Ornamental Research Site @ Dominican University Program Manager, San Rafael, CA, U.S.A.; (2) NORS-DUC, San Rafael, CA, U.S.A.; (3) CDFA, Sacramento, CA, U.S.A.

Phytopathology 105(Suppl. 4):S4.165

A more thorough understanding of the host range of Phytophthora tentaculata is an essential component to help inform restoration practitioners on risk reduction practices and the types of high-risk plants to avoid growing and planting. A prioritized list of the primary types of CA native plants being propagated to incorporate into restoration projects was selected. Input from native plant nurseries, resource conservation districts and consultants established this list for host range research at the National Ornamental Research Site at Dominican University of CA (NORS-DUC). To date, seven key species have been tested. Of this group, only the known host, Mimulus aurantiacus, was found to be susceptible. This expanding knowledge base will aid producers in their selection of mitigation measures to reduce the risk of introducing the pathogen into their operations and the potentially serious consequences of out-planting infected stock into the native habitat.

\section{New advances in molecular diagnostics for Phytophthora tentaculata}

T. D. MILES (1), F. N. Martin (2)

(1) California State University Monterey Bay, Seaside, CA, U.S.A.; (2) USDA-ARS, Salinas, CA, U.S.A.

Phytopathology 105(Suppl. 4):S4.165

Phytophthora tentaculata has become an important invasive pathogen in restoration nurseries along coastal California. Recently, two mitochondrial

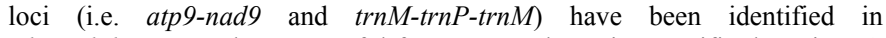
Phytophthora spp. that are useful for genus and species specific detection. A significant sequence database for both loci was developed from isolates that were obtained from the World Phytophthora Genetic Resource Collection. Using these mitochondrial loci a TaqMan species and genus specific assay was developed for 50 Phytophthora spp., one of which was P. tentaculata. This $P$. tentaculata specific TaqMan assay is sensitive down to 50-100 fg of purified DNA, has been tested for specificity on over 130 Phytophthora taxa and been validated on $P$. tentaculata-infected plant tissue. Furthermore, a new isothermal diagnostic technique known as recombinase polymerase amplification has been developed using these same mitochondrial loci that allows for genus and species specific detection of $P$. tentaculata directly in the field without the need for DNA extraction. Hopefully with the development of these tools researchers and regulators can actively track $P$. tentaculata on infected plant material and in environmental samples to develop best management practices for its control in the nursery system.

Studies in the use of heat to control Phytophthora tentaculata

W. SCHWEIGKOFLER (1), K. Kosta (2), S. Sharma (1), A. Santiago (1), S. Ditta (1), V. Huffman (1), K. Suslow (1)

(1) Dominican University of California, San Rafael, CA, U.S.A.; (2) California Department of Food \& Agriculture, Sacramento, CA, U.S.A.

Phytopathology 105(Suppl. 4):S4.165

$P$. tentaculata is a pathogen of herbaceous plants and has been found in nurseries in Europe and China. In fall of 2012, P. tentaculata was isolated from Sticky monkey flower, Mimulus aurantiacus (Phrymaceae), in coastal California. Since then, $P$. tentaculata was found in several native plant nurseries and restoration plantings. Most probably, the pathogen can spread via infected nursery material. Recently we have shown that thermal treatment by steaming can be used to inactivate $P$. ramorum, the causal agent of Sudden Oak Death and Ramorum blight, from nursery plants, soil and equipment. In order to test if heat treatment could also be used to control $P$. tentaculata, we tested the effect of dry and wet heat on the survival rate of $P$. tentaculata in the lab. Two other Phytophthora species recently isolated from Rhododendron at NORS-DUC, namely $P$. syringae and $P$. c $f$. fallax, were included in the study. Whereas $P$. syringae is a well-known nursery pathogen, $P$. fallax was previously only described from Eucalyptus trees in New Zealand. Because $P$. tentaculata does not grow on Rhododendron leaves (the leaf baiting material for $P$. ramorum), we tested the survival of $P$. tentaculata grown on agar plugs. Incubation at $50^{\circ} \mathrm{C}$ inactivated all tested Phytophthora strains. The effect of steaming was tested successfully at the NORS-DUC research nursery using a commercial steaming unit (SIOUX Steam-Flo SF-1); no Phytophthoras were re-isolated from the post-steaming soil.

Implementing a systems approach of best management practices in native plant nurseries

\section{K. L. KOSTA (1)}

(1) California Dept of Food and Agriculture, Sacramento, CA, U.S.A.

Phytopathology 105(Suppl. 4):S4.165

The discovery of $P$. tentaculata in native plant nurseries and restoration sites in California has raised the age old question "How did it get there?" Propagative stock is collected in the wild, new soil and clean water is typically used in their production systems. This pathogen was not known to occur in North America. The cryptic introduction of pathogens leaves one questioning how to protect themselves against plant diseases. A systems approach to production that involves employment of best management practices throughout the growing process from cradle to grave is being implemented across the entire agricultural and horticultural industries worldwide and appears to be the new standard. The California Department of Food and Agriculture Best Management Practices Program for Ornamental and Native Plant Nurseries is working closely with nurseries, as well as restoration sites, to install programs to prevent the introduction of pathogens and prevent further spread of those within the nursery or field site. The nature of the processes for producing native plants differs from those used in the ornamental nurseries. The California native plant nursery community is fully invested in the development of an all inclusive program from seed collection to distribution of the final product.

Evaluating the efficacy of the systems approach at mitigating five common pests in Oregon nurseries

N. K. OSTERBAUER (1), M. Lujan (1), G. McAninch (1), S. Lane (1), A. Trippe (2)

(1) Oregon Department of Agriculture, Salem, OR, U.S.A.; (2) Oregon State University, Corvallis, OR, U.S.A.

Phytopathology 105(Suppl. 4):S4.165

In Oregon, the U.S. Nursery Certification (USNCP), Grower Assisted Inspection (GAIP), and Shipping Point Inspection (SPI) programs are used to certify nursery plants as pest free. To compare the programs' effectiveness for mitigating pest risk, potted plants grown within two USNCP, two GAIP, and two SPI nurseries were surveyed for Phytophthora root rot (Phytophthora spp.), Phytophthora foliar blight (Phytophthora spp.), bittercress (Cardamine spp.), snails and slugs (Class Gastropoda), and root weevils (Otiorhynchus spp.). A total of 1,635 plots were surveyed in the nurseries, with one or more pests detected in 1,003 plots. Based on the total percentage of plots found infested with a pest, significantly fewer were detected in the GAIP nurseries $(55 \%)$ than in the USNCP nurseries (68\%). However, bittercress incidence was significantly higher in GAIP nurseries (21\%), while snails and slugs incidence was significantly higher in USNCP nurseries (49\%), and 
Phytophthora root rot incidence was significantly higher in SPI nurseries (31\%). Also, the plant families grown by the nurseries had a significant impact on pest incidence for two of the target pests, Phytophthora root rot and root weevils. While the GAIP seemed the best at mitigating pest incidence overall, none of the certification programs was consistently the most effective against all five target pests.

A systems approach to nursery and greenhouse phytosanitary certification (SANC) for plant production facilities in the U.S.

R. WELLIVER (1)

(1) Pennsylvania Department of Agriculture, Harrisburg, PA, U.S.A.

Phytopathology 105(Suppl. 4):S4.166

Phytosanitary certification at the international, interstate, and intrastate levels has relied primarily on single inspections or on compliance agreements tied to specific pests of regulatory concern. This leaves certifying agencies and plant producers unprepared for new pests. Any certification or compliance arrangement must be overhauled to include that new pest, resulting in a halt to plant sales for the affected nursery industry. The National Plant Board (NPB), an organization of state plant regulatory officials, has joined with industry, university, and USDA partners to cement a new program of state-level plant certification that relies on creation of a systems approach to pest management in participating plant production facilities. The facility and the state certifying agency work together to assess risk of pest introduction and movement in the facility, identify critical control points, and develop a system of best management practices (BMPs) to mitigate pest movement. This systems approach to nursery certification (SANC) should ease the blocks to normal business practice that pests of regulatory concern can cause, while also improving the quality and pest status of certified nursery stock. A pilot program for SANC is underway in 8 facilities across 8 states in 2015; plans are to expand the pilot in the next two years before offering the SANC Program to all interested parties as an alternative to load-by-load inspectionbased certification.

P. ramorum: Successes, failures and lessons learned that can be applied to P. tentaculata

R. BULLUCK (1)

(1) USDA APHIS PPQ CPHST, Raleigh, NC, U.S.A.

Phytopathology 105(Suppl. 4):S4.166

Phytophthora ramorum was first discovered in nurseries more than a decade ago causing disease on ornamental plants. Since that time, the pathogen has been regulated in interstate nurseries in the western states. The USDA APHIS PPQ and our State partners have learned a great deal about $P$. ramorum and its behavior in nurseries. For the past 6 years, research on $P$. ramorum has been conducted at the National Ornamental Research Site at Dominican University of California (NORS-DUC). The information on disease development, potential locations of primary inoculum and pathogen mitigation that has been developed over the past decade in regulated nurseries and in NORS-DUC have been invaluable. This information could be useful to apply to other nurseries with oomycetes, such as Phytophthora tentaculata. We will explore the potential application of the $P$. ramorum information to $P$. tentaculata and other exotic oomycetes in nursery systems.

\section{Disease Control and Pest Management}

\section{Banana Production at the Crossroads: Impact of Fusarium oxysporum f. sp. cubense TR4}

Detection, identification and the epidemiology of Fusarium oxysporum f.sp. cubense, Tropical Race 4

G. H. KEMA (1), N. I. Ordonez (1), M. Salacinas (1), C. Schoen (1), O. Mendes (1), C. Waalwijk (1), M. F. Seidl (1), A. Drenth (2)

(1) Wageningen University and Research Center, Wageningen, Netherlands; (2) The University of Queensland, Brisbane, Australia

Phytopathology 105(Suppl. 4):S4.166

Panama disease hits global banana production again. A new highly pathogenic strain of the devastating Fusarium oxysporum f.sp. cubense (Foc), commonly called Tropical Race 4 (TR4), infects Cavendish bananas as well as many local varieties, thereby threatening global banana production. We have genotyped all Foc vegetative compatibility groups (VCGs) using highresolution genome wide techniques. This has resulted in unique fragments enabling the development of precise molecular diagnostics that return results in minutes compared to VCG analyses that can take months. Using these technologies we have analysed recent incursions into Jordan, Lebanon and Pakistan and compared TR4 strains from these countries with strains from other geographical areas, and complemented the genotyping data by resequencing. The generated data show that TR4 - likely - represent a single clonal lineage that disseminates globally. This underscores the importance of awareness campaigns and through quarantine practices to avoid new continental leaps, which will have dramatics effects on producers and linked industries, similar to the previous Panama disease epidemic in Latin America in the previous century. The latest data will be presented and discussed.

The spread and impact of Fusarium oxysporum f.sp. cubense, Tropical Race 4 on global banana production

A. B. MOLINA (1), A. Viljoen (2), F. Dusunceli (3)

(1) Bioversity International, Los Banos, Philippines; (2) Stellenbosch University, Stellenbosch, South Africa; (3) Food and Agriculture Organization (FAO) of the United Nations, Rome, Italy

Phytopathology 105(Suppl. 4):S4.166

Recent epidemics of Fusarium wilt on Cavendish bananas in Asia recall the destruction caused by Race 1 of the pathogen, Fusarium oxysporum $f$. $s p$. cubense (Foc), to Gros Michel in Central America in the 1950s. Foc strain VCG1213/16, known as tropical race 4 (TR4), first destroyed Cavendish plantations in Taiwan, Indonesia and Malaysia in late 1900s. It has since affected more than 40000 ha in southern China and 8000 ha in the Philippines, and was recently found in the Middle East (Jordan, Oman) and Africa (Mozambique). Epidemics are primarily associated with monoculture Cavendish production. Occurences in small-scale diversified farming systems are often less severe. Research in Asia, by Bioversity International and regional partners, has yielded promising prospects to mitigate the disease, including use of inoculum-reducing practices and use of resistant Cavendish somaclones from Taiwan. Raising awareness on the spread and potential impact of the disease is crucial. The recent continental leap of Foc TR4 underscores the vulnerability of global banana production, including the Cavendish export industry in Latin America and large-scale monoculture production in India and Brazil. A Consortium was established to prevent the fungus in Mozambique from further spreading in Africa, where bananas are consumed as a staple food. A global FAO-led initiative was set up to prevent the further spread of Foc TR4 and reduce its impact on global banana production.

Tropical Race 4 of Panama disease threatens export and smallholder production of banana

R. C. PLOETZ (1)

(1) University of Florida, Homestead, FL, U.S.A.

Phytopathology 105(Suppl. 4):S4.166

Banana, Musa spp., is an important cash and food crop in the tropics and subtropics. Panama disease (aka Fusarium wilt) is caused by a variable pathogen, Fusarium oxysproum f. sp. cubense (Foc). The disease devastated the early 'Gros Michel'-based export trades, and a "new" variant of Foc, tropical race 4 (TR4), affects Cavendish cultivars that were used to replace 'Gros Michel' and which are now responsible for $40 \%$ of all production. Perennial production of this crop and the polycyclic nature of this disease hinder the development of effective management strategies; in most situations, the only effective measures are the use of resistant cultivars and pathogen exclusion. Until recent reports in Africa and Western Asia, TR4 was found only in the Far East. Better information is needed on how the pathogen moved the distances that were implicated in these outbreaks. Understanding how this occurred would be an important first step in slowing its spread, as managing this problem is much more difficult once an area is infested. There is an urgent need to improve resistance to TR4 in commercially acceptable genotypes of banana. The epidemiology and management of this disease are reviewed, as is the future of export and smallholder production. 


\section{Buzzing the Tower: Unmanned Aerial Vehicles (UAV)/ Drones for Applications in Plant Pathology}

Drone-ing for plant pathogens in agricultural ecosystems

D. G. SCHMALE (1)

(1) Virginia Tech, Blacksburg, VA, U.S.A.

Phytopathology 105(Suppl. 4):S4.167

New technologies are needed to track the long distance movement of plant pathogens in the atmosphere. We have developed a series of drones (unmanned aerial vehicles (UAVs)/ unmanned aircraft systems (UAS)) to study the transport of plant pathogens tens to hundreds of meters above crop fields. These drones are equipped with a variety of different devices for collecting microbes in the atmosphere during flight. Autonomous systems have been incorporated into some of these drones, enabling teams of aircraft to perform complex atmospheric sampling tasks (e.g., simultaneous sampling at multiple heights in the atmosphere) and coordinate flight missions with one another. Data collected with drones can be used to validate and improve disease forecasting models across a transport continuum-across farms, regions, and even continents. Atmospheric features known as Lagrangian coherent structures (LCSs) may carry and mix plant pathogens along 'highways in the sky'. Growers can use risk information from drone sampling missions to make appropriate plant disease management decisions, such as the timely application of appropriate fungicides. There are a number of unique, interdisciplinary opportunities involving drones to excite, engage, and train the next generation of plant pathologists, aerobiologists, and aerospace engineers.

A success story from 20 years of use of UAV (Yamaha RMAX) for crop dusting in Japan and experimentation in California grape production

K. GILES (1)

(1) University of California, Davis, CA, U.S.A.

Phytopathology 105(Suppl. 4):S4.167

No abstract available.

Autonomous aerial robots for precision farming

J. DAS (1)

(1) GRASP Laboratory, University of Pennsylvania, Philadelphia, PA, U.S.A.

Phytopathology 105(Suppl. 4):S4.167

Aerial robots or unmanned aerial vehicles (UAVs) capable of safe autonomous flights in unstructured farmlands will enable persistent monitoring of crop health through close-range sensing. This capability can provide many benefits to growers, such as improved yield and efficient use of resources such as water, fertilizer, and pesticides. We describe the design and development of a robotic sensing methodology that exploits a light-weight and low-cost multi-spectral 3-D imaging system mounted aboard low-flying multirotor UAVs to monitor a range of plant physiological and morphological properties. Weighing under $2 \mathrm{~kg}$, the imaging system consists of a laser range scanner, multi-spectral cameras, a thermal imaging camera, and navigational sensors. Onboard autonomy relies on powerful state-estimation and control algorithms to localize the UAV in GPS-denied environments. Actionable intelligence is extracted from the data acquired by the system, for example, currently we estimate four properties that are of interest to farm owners plant morphology, plant vigor, leaf area, and fruit counts. Results from multiple field trials conducted in collaboration with growers and agronomists in vineyards, apple orchards, and orange groves will be presented. Extended to a swarm of autonomous UAVs, our system will enable monitoring of large farmlands within tight time windows.

UAVs for orchard management: Prospects and procedures for aerial monitoring of plant health status in the Northeastern U.S.

M. WALLHEAD (1), K. D. Broders (1)

(1) University of New Hampshire, Durham, NH, U.S.A.

Phytopathology 105(Suppl. 4):S4.167

Unmanned aerial vehicles (UAV, UAS, SUAS, drone) meet the demand for a fast, sensitive and selective platform for the rapid detection of plant health status at the field or regional scale. In combination with passive and active remote sensors UAVs can provide rapid, accurate and reliable detection of plant diseases during the early stages of infection in order to minimize economic losses and maximize crop yields. The objective of this study was to develop an affordable multirotor UAV $(<\$ 2500$ USD) for the tracking and management of apple scab, caused by the fungal pathogen Venturia inaequalis. Results of this study confirm that a low-cost multirotor UAV is able to provide insight into plant health status and aid in the tracking and management of apple scab. Remote sensed data acquired from sensors onboard UAVs provide radically new perspectives on monitoring the status of plant health by allowing growers and crop advisors to rapidly and periodically detect areas of stress in a crop and manage issues immediately. Perhaps most importantly, UAVs allow for the targeted application of inputs and preventative actions based on real-time field conditions. The objective of this presentation is to provide a systems overview of UAVs commonly utilized for agricultural management and procedures related to flight-planning, piloting UAVs, and associated image processing and data management.

Development of a high-resolution remote sensing system for agricultural applications

D. HOLMAN (1), P. Gowda (2), M. Sridharan (3), D. Porter (4), T. Marek (5), J. Moorhead (2)

(1) Texas A\&M AgriLife Research, Lubbock, TX, U.S.A.; (2) USDA-ARS Conservation and Production Research Laboratory, Bushland, TX, U.S.A.; (3) University of Auckland, Auckland, New Zealand; (4) Texas A\&M AgriLife Extension Service, Lubbock, TX, U.S.A.; (5) Texas A\&M AgriLife Research, Amarillo, TX, U.S.A.

Phytopathology 105(Suppl. 4):S4.167

Development of a high-resolution remote sensing system would benefit many agricultural applications that use multi-spectral imagery as input. This study gives an overview of three high-resolution remote sensing-based applications: estimation and mapping of evapotranspiration (ET), plant characteristics, and crop yield. The Bushland Evapotranspiration And Remote Sensing System (BEARS) is being developed to simplify the complexity of ET map generation and provide an operational remote sensing problem for irrigation scheduling purposes. BEARS capabilities also include spatial interpolation of climatic variables and reference ET, raster data visualization and numerous GIS techniques for managing remote sensing data, ET maps and other products. For crop yield mapping a deep architecture based on artificial neural networks is being applied on historical crop yield averages to discover spatial and temporal relationships in plant reflectance across multiple bands. Finally, a plant breeder application is being developed to use UAV-mounted hyperspectral and thermal sensors to discover patterns and correlations between plant characteristics and finely tuned spectral reflectance. Each application has its benefits, and both satellite- and UAV-based remote sensing can offer significant benefits for agricultural applications.

\section{Impact of Innovative Postharvest Practices on Trade and Food Safety}

\section{Risk management strategies for microbial food safety in apples}

K. KILLINGER (1)

(1) Washington State University - University of Idaho School of Food Science, Pullman, WA, U.S.A.

Phytopathology 105(Suppl. 4):S4.167

Produce food safety standards focus on minimizing risk during packing. Whole, fresh tree fruit have been linked with Listeria monocytogenes recalls. Antimicrobial interventions in dump tanks, flumes and spray bars during apple packing must be validated using industry-relevant parameters. Replicated laboratory and industry studies investigated chlorine $(750-850 \mathrm{mV})$, chlorine dioxide $(750-850 \mathrm{mV})$ and peroxyacetic acid (PAA) at $40-80 \mathrm{ppm}$. Common industry spray bar applications (2-9s direct contact) using $80 \mathrm{ppm}$ PAA did not significantly reduce generic $E$. coli levels compared to water; however, 30s of direct contact with 60 or $80 \mathrm{ppm}$ PAA significantly reduced generic $E$. coli on apples. In low organic load dump tank applications (2.2-3.9min) $80 \mathrm{ppm}$ PAA produced a significant $1-\log$ reduction. In one industry dump tank system at low organic load, chlorine and chlorine dioxide slightly reduced generic E. coli levels on apples. However, in a unique industry dump tank, high pressure wash and flume system, chlorine and 
chlorine dioxide treatments significantly reduced generic E. coli. Results in industry facilities were influenced by organic load, water system management, order of packing equipment and antimicrobial activity. Collectively, laboratory and industry experiments indicated that the most common apple packing practices prevent cross-contamination but do not reduce generic $E$. coli on apples. Alternative practices to enhance microbial reduction were identified.

Systems approach-based mitigation of postharvest diseases to overcome trade barriers for Washington apples

C. L. XIAO (1)

(1) USDA-ARS, SJVASC, Parlier, CA, U.S.A.

Phytopathology 105(Suppl. 4):S4.168

Speck rot caused by Phacidiopycnis washingtonensis and Sphaeropsis rot caused by $S$. pyriputrescens were reported as new postharvest fruit rot diseases in Washington State in the mid-2000s. Both diseases can cause significant postharvest losses of fruit if left uncontrolled and the two fungi have been listed as quarantine pathogens to certain overseas markets. The two fungi can cause canker and twig dieback of crabapple (used as pollinators) and apple trees, infect apple fruit in the orchard, and remain latent before harvest, leading to postharvest fruit rots. A series of research has been conducted to determine the sources and availability of inoculum in orchards and timing of apple fruit infection in the field in relation to the development of postharvest fruit rots, and develop pre- and postharvest chemical strategies for control of the diseases. A systems approach-based mitigation to meet export requirements is based on the biology and epidemiology of the diseases and includes a series of pre- and postharvest practices targeting various components of the disease development from orchard to storage and marketing channel. The development of the mitigation measure will be discussed.

Thermofogging - innovative technology to control fruit decays without potential food safety concerns

Y. K. KIM (1)

(1) Pace International, Wapato, WA, U.S.A.

Phytopathology 105(Suppl. 4):S4.168

Fruit loss due to postharvest fungal diseases is one of the most challenging barriers to overcome in pome fruit industry worldwide. Recirculating drenches have been widely used for several decades to apply fungicides before storage to control the postharvest diseases. Typically applied within a few days of harvest, recirculating drenches are highly effective in controlling major decays with current postharvest fungicides. Alternatively, disadvantages are accumulation of decay pathogens in the solution, reduction of efficacy due to dirt and dust in the solution, and environmental concern of solution disposal. More recently, the concern is that human pathogens might be transferred from bin runners into the drench solution and could potentially contaminate tons of sound fruit. Alternative methods, such as pre-harvest fungicide sprays and non-recirculating single-bin drenches in the orchard substantially reduce the diseases compared to untreated fruit; however, these methods are not as effective as the recirculating drenches. Thermo-fogging is an innovative technology that applies postharvest fungicides without compromising the efficacy and does not have the disadvantages of recirculating drenches, including potential food safety concerns. This presentation will discuss current status of the technology and recent innovations.
New biopesticide and exempt-from-tolerance postharvest treatments to manage fruit decays in the United States

J. E. ADASKAVEG (1), H. Forster (1)

(1) University of California, Riverside, CA, U.S.A.

Phytopathology 105(Suppl. 4):S4.168

Postharvest fungicides registered in recent years in the U.S. for decay management belong to the safest pesticides ever available. Still, some consumers and export markets perceive naturally derived and exempt-fromtolerance compounds as more acceptable for treating food crops. Therefore, efforts have increased in identifying such compounds that may also benefit from an accelerated registration. Our research is developing biopesticide and exempt-from-tolerance fungicides that show comparable efficacy to conventional postharvest treatments. Potassium phosphite, with exempt status in the U.S., is now registered for postharvest use to manage citrus brown rot caused by Phytophthora spp. International tolerances are being pursued. It was as effective as other fungicides in protecting fruit when applied before inoculation but was the only treatment with post-infection activity. PolyoxinD, a fermentation product of a Streptomyces sp., has a U.S. biopesticide registration for field use on various crops. We found it similarly effective to conventional postharvest fungicides against gray mold and brown rot of stone fruits and it is currently being registered. We are also evaluating the potential biopesticide EXP-13 for control of Penicillium decays of citrus and pome fruits. This compound with a low resistance potential can be a mixture partner with other fungicides in an effort to minimize resistance development and reduce total pesticide amounts on these crops.

Postharvest processing technologies to improve food safety and quality B. A. NIEMIRA (1)

(1) USDA-ARS Eastern Regional Research Center, Wyndmoor, PA, U.S.A. Phytopathology 105(Suppl. 4):S4.168

Contamination of fresh and fresh-cut fruits and vegetables by foodborne pathogens is an ongoing problem. The limitations of conventional sanitation methods have prompted research into novel interventions. In addition to advanced applications of gas-phase chemical sanitizers, several promising physical treatments are in development. Cold plasma is a nonthermal food processing technology which uses energetic, reactive gases to inactivate contaminating microbes. This flexible sanitizing method uses electricity and a carrier gas such as air, oxygen, nitrogen or helium; antimicrobial chemical agents are not required. The primary modes of action are via reactive chemical products of the cold plasma ionization process and UV light. Reductions of greater than $5 \operatorname{logs}$ can be obtained for pathogens such as Salmonella and Escherichia coli O157:H7. Additional treatments rely on precise applications of high intensity light, either as pulsed broad-spectrum exposures, or as a narrow-band, monochromatic light treatment. This presentation will summarize the science behind these technologies and describe recent advances. Finally, key areas of future research will be described that will facilitate commercialization.

Where have all these emergent downy mildews come from? Using herbarium collections and comparative genomic tools to retrace pathogen populations

J. A. CROUCH (1)

(1) USDA-ARS-SMML, Beltsville, MD, U.S.A.

Phytopathology 105(Suppl. 4):S4.168

No abstract available.

\section{Diseases of Plants}

\section{Emerging Downy Mildew Diseases: Where Have We Been, Where Are We Going?}

The utility of comparative mitochondrial genomics of downy mildews for development of molecular tools for identification and diagnostics F. N. MARTIN (1)

(1) USDA-ARS, Salinas, CA, U.S.A.

Phytopathology 105(Suppl. 4):S4.168

One of the challenges of working with downy mildews (DMs) is their obligate nature, limited morphological differences for classification (especially for detached sporangia) and lack of a comprehensive sequence database useful for species identification. In an effort to facilitate development of molecular tools for working with this group of pathogens a comparative mitochondrial genomics approach has been used. Over 210 mitochondrial genomes from a wide range of oomycetes, in particular downy mildews, Pythium and Phytophthora, have been assembled and used to identify useful loci and conserved primers for their amplification. Several targets are under evaluation for their ability to be amplified from a wide range of DMs and their utility for species identification, phylogenetics and metagenomic analysis. Unique sequences and gene order differences in DMs relative to other oomycetes are under evaluation with collaborators for development of diagnostic markers for several DMs. Mitochondrial genomes for multiple isolates of several DMs have been assembled, providing insight on genome evolution and mitochondrial haplotype markers for genetic analysis and population studies. The progress of these projects and the potential application of the assembled database for working with a broader range of downy mildews will be discussed. 
How can we minimize our losses? Control strategies in downy mildew systems

M. HAUSBECK (1)

(1) Michigan State University, East Lansing, MI, U.S.A.

Phytopathology 105(Suppl. 4):S4.169

Emergent and reemergent downy mildews (DM) are highly destructive and adaptable plant pathogens. In the last decade, cucurbit (Pseudoperonospora cubensis), basil (Peronospora belbahrii), impatiens (Plasmopara obducens), and coleus (Peronospora sp.) DMs have devastated industries valued at nearly $\$ 8$ billion USD. Host resistance is either unavailable or has been overcome by new pathogen isolates or races. Understanding pathogen epidemiology and populations can assist with developing resistant cultivars and management strategies. Some DM pathogens have proven adept at moving great distances each year via wind-dispersed spores, thus they cannot easily be avoided. In the absence of resistant cultivars and effective bio-controls, fungicides are critical for limiting economic losses. For cucurbits, fungicides may need to be applied as frequently as every 5 days with an estimated cost of $\$ 6$ million per year in Michigan alone. Some DM pathogens have become insensitive to key fungicides, thereby threatening crops. P. cubensis populations have demonstrated resistance to mefenoxam, strobilurins, fluopicolide, and mandipropamid. In impatiens DM, resistance to mefenoxam was identified in Michigan and Florida populations. Mefenoxam resistance has been reported in sweet basil in Israel. Current recommendations for growers combine cultural practices (reducing planting density, manipulating environmental conditions, and planting less susceptible cultivars) with fungicides.

Predicting epidemics: Risk assessment and role of host susceptibility in cucurbit downy mildew outbreaks

P. OJIAMBO (1)

(1) North Carolina State University, Raleigh, NC, U.S.A.

Phytopathology 105(Suppl. 4):S4.169

Cucurbit downy mildew, caused by the oomycete Pseudoperonospora cubensis, has resurged in the US resulting in a significant impact on cucurbit production and management of the disease at different spatial scales. Understanding the spread of cucurbit downy mildew epidemics at a local and regional scale is fundamental in the management of the disease at multiple scales. In the US, the seasonal spread of the disease that is characterized by typical extinction-colonization makes it possible to quantify the dynamics and risk of disease outbreaks in northern latitudes based on epidemic conditions and inoculum dispersal from the overwintering habitat in the south. Risks of disease outbreaks in the continental US are quantified using Bayesian hierarchical spatial models and risk of disease outbreak is estimated to be high in the mid-Atlantic region. Disease dynamics indicate that the rate of spread of the epidemic wave front in spring-planted annual crop is limited by the seasonal advance of host planting and the epidemic wave is estimated to advance northward at a rate of $12 \mathrm{~km} /$ day. Weather factors that influence the risk of disease outbreak at a local scale have been quantified and used to estimate the potential risk of infection based on forecasted temperature and leaf wetness. Host susceptibility can influence risk of disease outbreak at different scales but estimated risk based on most susceptible hosts are probably more practical decision support tool for growers.

Comparative genomics of inter- and intra-specific variation in downy mildews

R. MICHELMORE (1), L. Derevnina (1), S. Reyes-Chin-Wo (1), K. Wood (1), J. Wong (1), F. Martin (2), J. Gil (1), C. Tsuchida (1), I. Simmon (1), S. Klosterman (2), C. Magill (3), O. Spring (4), R. Sharma (5), R. Varshney (5), O. Ochoa (1)

(1) University of California, Davis, Davis, CA, U.S.A.; (2) USDA ARS, Salinas, CA, U.S.A.; (3) Texas A\&M, College Station, TX, U.S.A.; (4) University of Hohenheim, Hohenheim, Germany; (5) ICRISAT, Hyderabad, India Phytopathology 105(Suppl. 4):S4.169

Downy mildews (DMs) are oomycete pathogens that cause disease on a wide range of crop plants. Individual species have narrow host ranges and exhibit high degrees of host specialization. We utilized high throughput sequencing to generate de novo genome assemblies of geographically and temporally separated isolates of Bremia lactucae (lettuce DM), Peronospora effusa (spinach DM), P. schachtii (chard DM), P. tabacina (tobacco DM), Peronosclerospora sorghi (sorghum and maize DM), and Sclerospora graminicola (pearl millet DM). These genome assemblies were highly syntenic but varied greatly in size $(50-\sim 320 \mathrm{Mb})$, gene content $(12-20 \mathrm{~K})$, repeat content $(15-$ $\sim 60 \%$ ), and repertoire of genes encoding effectors and other pathogenicityrelated proteins. No families of RXLR-containing effectors are common across all DMs; however, RXLR families overlap greatly between isolates within a species. DM is the most important disease of lettuce in California and worldwide; $B$. lactucae is highly variable and can rapidly change to overcome resistant cultivars. We have monitored changes in virulence phenotypes of $B$. lactucae in California since 1982. The appearance of the $\mathrm{B}_{1}$ mating type may explain the recent increase in novel virulence phenotypes and may require a change in strategy for resistance gene deployment. Genomic sequence analysis of representative isolates collected in California and Europe over three decades provides detailed information of variation of $B$. lactucae.

\section{Physiological Basis and Modeling for Climate- Induced Changes in Forest Pathogens and Their Hosts}

\footnotetext{
Emergence of a new disease, bur oak blight, with recent increases in spring rainfall

T. C. HARRINGTON (1), D. McNew (1)

(1) Iowa State University, Ames, IA, U.S.A.

Phytopathology 105(Suppl. 4):S4.169

Bur oak blight (BOB) appeared on native bur oak (Quercus macrocarpa) in the 1990s and early 2000s in Minnesota, Iowa and neighboring states. Symptoms included mid- to late-season necrosis of leaf veins and dead leaves attached to twigs. Initially, conidiomata of the European leaf spot pathogen Tubakia dryina were associated with the necrotic leaf veins, but closer study led to the description of a new species, T. iowensis. Surveys of natural groves have shown a steady annual increase in disease levels, but variation in DNA sequences suggested that $T$. iowensis was indigenous. Further, BOB was found to be widespread throughout the range of $Q$. macrocarpa var. oliviformis, which is adapted to upland, savannah sites. Other Tubakia spp. were associated with veinal necrosis or leaf spots, but only $T$. iowensis formed overwintering conidiomata on petioles attached to twigs. Infection of emerging shoots during wet periods in late April and May resulted in a 2 mo or more latent phase, with petiole necrosis in July and non-abscising leaves in fall, providing the overwintering inoculum. Consecutive springs of average or above rainfall appear to lead to build up of BOB in individual trees. Spring rainfall has increased $50 \%$ in recent years in Iowa, which has not had two consecutive springs of below-average rainfall since 1989. Mature bur oak established on these former savannah sites in an epoch of drier springs, without selection for the resistance needed in today's climate.
}

Differential fitness in ecotypes of the pitch canker pathogen: Implications for climate change and forest health

T. QUESADA (1), J. A. Smith (1)

(1) University of Florida, Gainesville, FL, U.S.A.

Phytopathology 105(Suppl. 4):S4.169

Pitch canker, caused by the necrotrophic fungus Fusarium circinatum, is one of the major diseases in pines, affecting forests and commercial plantations worldwide. Depending on environmental factors, major outbreaks may occur or the pathogen may remain latent as an endophyte without causing symptoms. Increased global temperatures and altered precipitation regimes may favor conditions for pitch canker, but the current mitigation strategies rely mainly on breeding and selection of resistant host material, which takes many years to achieve. Preliminary data on growth at high temperatures (25, 28 , and $31^{\circ} \mathrm{C}$ ) show significant changes between fungal isolates collected from throughout Florida, suggesting latitude-associated differential response to temperature stress. Our current knowledge on species-wide host susceptibility in clonally propagated loblolly pine creates the ideal platform to manipulate all corners of the disease triangle to assess the effects of this disease in a changing climate. Effects of temperature stress on sporulation and pathogenicity of $F$. circinatum isolates will also be addressed. Studying the effects of a changing climate on pitch canker disease would improve understanding of host-pathogen systems. This would allow the development of adequate prediction models for implementation of more efficient mitigation strategies aimed at improving forest health.

Ecology of Swiss needle cast in Western Oregon Coastal forests: Ecophysiology and tree ring analysis correlate intensification to climate warming D. C. SHAW (1)

(1) Dept. of Forest Engineering, Resources, and Management, Oregon State University, Corvallis, OR, U.S.A.

Phytopathology 105(Suppl. 4):S4.169 
Phaeocryptopus gaeumannii, cause of Swiss needle cast of Douglas-fir (Pseudotsuga menziesii), has intensified in western Oregon and Washington, USA since 1980 's. Manter and colleagues demonstrated P. gaeumannii, an endophytic biotroph, caused disease by carbon starvation due to ascocarps (pseudothecia) plugging the stomates. $\sim 25 \%$ stomatal occlusion was associated with no net carbon gain for a leaf. Manter et al. used field, laboratory, and greenhouse studies to build an epidemiology model that included Dec, Jan, Feb mean daily temperature and a leaf wetness factor for May, June and July (the period of potential spore dispersal). Saffell et al. used fungicide treated and un-treated trees to demonstrate carbon stable isotope discrimination $\left(\Delta^{13} C\right)$ of treated Douglas-fir was greater than untreated and used tree ring analysis to predict precipitation in the previous 2 summers most influenced disease. Black and colleagues demonstrated that dendrochronology could be used to find a tree-ring-reduced-growth signal and indicated that deviation in growth from a companion species (Tsuga heterophylla) has occurred since the 1980's. Black et al. developed a climatebased disease severity model using data from 3 sites that linked MarchAugust temperature to intensification of disease and showed a correlation with 1960-2000 weather records when consistent warming occurred during these months.
Risk of forest diseases given climate change: Case study of Phytophthora ramorum

S. J. FRANKEL (1), R. C. Cobb (2)

(1) USDA Forest Service, Pacific Southwest Research Station, Albany, CA, U.S.A.; (2) Department of Plant Pathology, UC Davis, Davis, CA, U.S.A.

Phytopathology 105(Suppl. 4):S4.170

Since it was first recognized in the mid1990s, Phytophthora ramorum has killed millions of tanoak, Notholithocarpus densiflorus, and coast live oak (Quercus agrifolia) trees along the Pacific Coast in California and Oregon. Symptom development, spread and mortality are linked to temperature and moisture conditions. El Niño conditions that increase rainfall in the spring aid pathogen spread while intense heat coupled with low precipitation levels incite mortality. Data from aerial survey, permanent plots and other reports clearly demonstrate an ebb and flow in disease intensity. Utilizing these apparent climatic relationships we present projections of how the pathogen will respond to climate change. Cursory risk assessments and models indicate a range of outcomes but decreased rain and increased summer temperatures would decrease pathogen spread while increasing mortality of infected trees. Previous work has demonstrated that pathogen populations recover quickly following multi-year drought indicating that $P$. ramorum will be a persistent factor affecting forest ecosystem structure and function along the Pacific Coast. Climate driven fluctuations of pathogen dynamics are a characteristic of this disease which is insufficiently integrated into management plans.

\section{Ecology and Epidemiology}

\section{Blocking the Transmission of Vector-Borne Plant Pathogens, Dream or Reality?}

Insights on virion retention (and inoculation): Implications for reducing the whitefly transmission of foregut-borne criniviruses

J. NG (1)

(1) University of California, Riverside, Riverside, CA, U.S.A.

Phytopathology 105(Suppl. 4):S4.170

Insect vector mediated transmission of plant viruses entails a continuum of three critically related but ill-understood processes: 1) acquisition of virions from the virus-infected plant during sap ingestion, 2) stable retention of virions in (and passage of virions through) specific sites within the insect vector, and 3) inoculation of the retained virions into a recipient plant. Research on criniviruses (including Lettuce infectious yellows virus [LIYV] and Lettuce chlorosis virus [LCV]) have shown that transmissible virions are retained in the foregut of specific whitefly (Bemisia tabaci) vectors; and retention of LIYV virions is mediated by a capsid protein component (the LIYV minor coat protein $[\mathrm{CPm}])$. Continuing efforts have aimed at using the $\mathrm{CPm}$ as a competitive inhibitor of LIYV transmission to further investigate its role in mediating virion retention and transmission. Presumably, the retained virions must switch from a retention mode to an inoculation mode in order to be delivered into a recipient plant during transmission. How this transition is achieved is unknown and is a subject of our current research. Elucidating the mechanisms underlying the processes involved in crinivirus transmission holds the potential for novel approaches aimed at breaking the continuum, thereby curtailing the transmission of not only these viruses, but possibly other foregut borne plant viruses as well.

RNAi strategies targeting hemipteran vectors of plant pathogens B. FALK (1), T. Pitman (1), Y. W. Kuo (1), S. Nouri (1), H. Wuriyanghan (2), C. Rosa (3), J. Warren (1)

(1) University of California, Davis, CA, U.S.A.; (2) Inner Mongolia University, Hohot, China; (3) Pennsylvania State University, University Park, PA, U.S.A.

Phytopathology 105(Suppl. 4):S4.170

RNA interference (RNAi) is a natural gene regulation and anti-viral defense found in a majority of eukaryotes, and is the primary anti-viral defense in plants and possibly insects. We are evaluating RNAi strategies against specific vascular-feeding hemipteran vectors of plant pathogens. We induced RNAi effects, including increased mortality and specific knockdown of target mRNAs in target insects by injecting specific, complementary doublestranded RNAs into the hemocoel. We were also able to induce RNAi effects in Bactericera cockerelli by feeding RNAi inducers in artificial diets. Because plants respond to virus infections by RNAi, we also investigated using recombinant plant viruses to deliver RNAi inducers to target insects feeding on the virus-infected plants. For both B. cockerelli and Planococcus citri we observed specific RNAi effects including target mRNA knockdown and nymph mortality when the respective insects were fed on plants infected with recombinant Tobacco mosaic virus expressing specific target insect interfering RNAs. We are now attempting to increase target insect specificity and reduce the potential for off-target effects by two additional approaches. One is by producing specific artificial microRNAs to target only the corresponding mRNA and the second is to identify and engineer insect viruses that might be useful for VIGs/HIGs in target insects. The results from these efforts will be discussed.

The acrostyle in aphid stylets: An Achille's heel for virus transmission? M. UZEST (1)

(1) National Institute for Agronomic Research (INRA), Montpellier, France Phytopathology 105(Suppl. 4):S4.170

More than 5,000 aphid species have been described around the world. Their reknown as major pests in agriculture relies mainly on their formidable capacity to transmit countless plant viruses to most important crops worldwide. They transmit hundreds of viruses in a non-circulative manner where the virus is retained on specific, yet totally unknown, receptors located in the aphids' stylets. Pesticide treatments have been extensively used in the past, and proved in many cases inefficient to prevent viral spread, because non-circulative viruses are acquired and inoculated within seconds. Targeting and disrupting specifically the interaction between viruses and their vectors has long been foreseen as an «environmentally friendly» alternative strategy to efficiently control crop diseases, but long-standing technical bottlenecks related to the nature of the insect stylets prevented its implementation. Over the last decade, we have produced data that bring this objective within possible reach. We have discovered the acrostyle, an organ located at the tip of aphids' maxillary stylets, which bears the receptors of Cauliflower mosaic virus (CaMV) and likely those of other viruses. Very recently, the first protein of the acrostyle has been identified and it is currently being further characterized. We show that one of its peptide domains is readily accessible at the surface, and that its localization overlaps the binding sites for CaMV, making it an ideal receptor candidate.

Disrupting circulative virus transmission by blocking virus-vector interactions

A. E. WHITFIELD (1)

(1) Kansas State University, Manhattan, KS, U.S.A.

Phytopathology 105(Suppl. 4):S4.170

Plant viruses are a significant threat to global food security, and the majority of viruses that infect plants are transmitted from one host to another by 
arthropod vectors. Due to the specificity of virus transmission by vectors, there are distinct steps in the transmission process that represent good targets for strategies to disrupt the disease cycle. Circulative viruses enter the vector body and disseminate to various tissues prior to their transmission to plant hosts. A specific viral protein(s) is required for attachment and/or entry into the insect vector. Exploiting these viral attachment proteins or their insect interaction partners is a logical approach for reducing transmission. Recombinant viral attachment proteins can be used to 1) decrease transmission efficiency by blocking virus entry and subsequent dissemination and 2) decrease the vector population size by using the viral protein to ferry toxic cargo into the vector. Specific vector molecules interact with the virus during circulative transmission and while there is limited information on receptors, candidate recognition molecules are being further explored in virus-vector systems. As virus binding-proteins are identified in vectors, they can be used to develop strategies to prevent virus acquisition and dissemination. Fundamental virus-vector interaction discoveries have enabled the development of pioneering strategies for breaking the cycle of transmission.
Blocking the vector transmission of non-circulative bacteria

R. ALMEIDA (1), N. Killiny (2), F. Labroussa (1)

(1) University of California, Berkeley, CA, U.S.A.; (2) University of Florida, Lake Alfred, FL, U.S.A.

Phytopathology 105(Suppl. 4):S4.171

Despite the importance of vector-borne plant diseases, management is still largely based on the application of pesticides to control vector populations, which has direct and indirect consequences to food production and environmental safety and sustainability. Recent research has led to a better understanding of vector-pathogen interactions, which can now serve as the basis for the development of new approaches to control plant diseases. We have studied interactions of the bacterium Xylella fastidiosa with its leafhopper vectors, identifying proteins involved in adhesion to and colonization of insect vectors. Using biochemical, in vitro, and greenhouse assays we have showed that specific molecules reduce $X$. fastidiosa binding to chitin and vector surfaces, in addition to vector transmission to plants, demonstrating that blocking of $X$. fastidiosa transmission is a feasible approach to control disease prevalence.

\section{Climate Cycles, Climate Forecasting, and Disease Cycles Spanning Multiple Years}

\author{
Weather prediction from climatology \\ G. H. TAYLOR (1) \\ (1) Applied Climate Services, Corvallis, OR, U.S.A \\ Phytopathology 105(Suppl. 4):S4.171
}

"Climate" and "weather" are related terms which describe patterns of temperature, precipitation, winds, humidity, and other characteristics of the atmosphere. They differ in time scale: "climate" represents atmospheric variables over long periods of time while "weather" describes short-term conditions in a given location or region. It is well-known that climate varies in a quasi-cyclical manner according to a large number of periodicities. These include the so-called "Milankovich" cycles, which span 25,000-100,000 year periods and appear to coincide with ice ages, to much shorter cycles such as the 2.2-year Quasi-biennial Oscillation. Some of the cycles appear to be internally-based within earth's ocean-atmosphere system, while others appear to be caused by external forcings (solar cycles, lunar tidal cycles). In addition to improvements in the scope and accuracy of weather and climate data, some innovative and powerful software tools are becoming available for analytical purposes. Two examples are Regional L-Moments, used for spatial distributions of meteorological and hydrological variables; and PRISM (Parameter-elevation Relationships on Independent Slopes Model), the stateof-the-art tool for spatial distributions in areas with complex topography.

\section{AgroClimate: Climate and weather information for monitoring and} predicting strawberry disease risk in Florida

\section{FRAISSE (1), N. Peres (1)}

(1) University of Florida, Gainesville, FL, U.S.A.

Phytopathology 105(Suppl. 4):S4.171

Climate associated production risks in agriculture include the spatial and temporal variability of rainfall, temperature, solar radiation, wind, and other factors influencing crop development an d growth. These factors can also affect the life cycle of plant diseases and pests. Strawberries in Florida are grown as annual crop, with the season from November to March, and require intensive management due to the high disease pressure. Anthracnose and Botrytis fruit rot are the main diseases affecting strawberry in Florida with fungicide applications to control these diseases representing about $15 \%$ of the total operating costs. The El Niño Southern Oscillation (ENSO) phenomenon is the main driver for climate variability in the Southeast USA during the strawberry production season. Excess or lack of moisture associated with ENSO phases can have significant impact on plant disease severity, since many pathogens are related to the period of time when free water remains on plants tissues. The AgroClimate Strawberry Advisory (SAS) was developed to monitor and predict disease risk based on weather data observed at the Florida Automated Weather Network stations. Growers can obtain a prediction of disease incidence and recommendations for fungicide application. Diseases risk levels and warnings of the need to spray can be sent by email or text messages. A mobile phone app has also been developed to facilitate the dissemination of the information to growers.

\section{Use of climate patterns in prediction of Fusarium head blight epidemics} A. B. KRISS (1), P. A. Paul (2), L. V. Madden (2)

(1) Syngenta, Greensboro, NC, U.S.A.; (2) The Ohio State University, Wooster, OH, U.S.A.

Phytopathology 105(Suppl. 4):S4.171

It is well-known that short-term weather conditions have significant relationships with Fusarium head blight (FHB) epidemics and forecast models have been developed that use weather conditions near flowering to predict the risk of disease. However, we have also identified longer time-scales during the wheat-growing season where environmental variables are associated with FHB intensity, which may be in response to larger-scale climate patterns. Climate patterns that affect the Midwest Region include the Oceanic Niño Index (ONI), the El Niño Southern Oscillation (ENSO), the Pacific-North American pattern and the North Atlantic Oscillation. These climate patterns and the time-series of FHB disease intensity observations over more than 45 years were investigated through wavelet and spectral analysis methods. These analytical methods identify the frequency at which a temporal signal occurs and clusters of years within the overall patterns where relationships are strongest. Results suggest that global climate indices and models could be used to identify years with high (or low) risk for FHB development, although the most accurate risk predictions will also require use of local weather data during key time periods. Research on new analyses methods to investigate climate/disease relationships, other plant pathogens that exhibit relationships with the climate, and integration of climate into current or new weather forecasting models is ongoing.

\section{Contributions from Population Genomics to Plant Pathology}

\section{The changing landscape of sequencing technologies} I. GRIGORIEV (1)

(1) US DOE Joint Genome Institute, Walnut Creek, CA, U.S.A. Phytopathology 105(Suppl. 4):S4.171

Genomics is a powerful and quickly evolving tool to understand processes of host-pathogen interactions. The Fungal Genomics Program (jgi.doe.gov/fungi) of the US Department of Energy (DOE) Joint Genome Institute (JGI) is partnering with international scientific community to explore the diversity of fungal plant pathogens and their interactions with plant hosts by offering several large scale genomics initiatives. Within one of these initiatives, the Genomic Encyclopedia of Fungi, we explore the interactions between bioenergy crop species with symbionts and pathogens. Another, the 1000 Fungal Genomes project, is aimed to explore diversity across the Fungal Tree of Life in order to provide references for every family of fungi and a solid basis for environmental metagenomics. Open to all scientists around the world, these initiatives result in massive amounts of genomic information 
integrated with analytical tools and community-driven experiments in the fungal genomics analytical resource MycoCosm (jgi.doe.gov/fungi), which currently offers data and tools for over 500 fungal genomes, genome variation, gene expression and other functional genomics data.

The making of a tree pathogen: Horizontal gene transfers, host jumps and speciation

R. C. HAMELIN (1), N. Feau (2), B. D. Dhillon (2), M. L. Sakalidis (2)

(1) Natural Resources Canada, Vancouver, BC, Canada; (2) University of British Columbia, Vancouver, BC, Canada

Phytopathology 105(Suppl. 4):S4.172

Tree pathogens cause some of the most devastating forest epidemics. In spite of their importance, we know relatively little about their origin and sources. We used a population genomics approach to study these questions in the poplar canker pathogen, Mycosphaerella populorum (anamorph: Septoria musiva syn. Sphaerulina musiva). This pathogen is presumed to have coevolved with the eastern cottonwood, Populus deltoides, but has recently been expanding to new hosts such as $P$. trichocarpa and $P$. balsamifera. Genome comparisons between $M$. populorum, which causes both leaf spots and cankers, and M. populicola, a close relative that also attacks poplar but does not cause cankers, indicate that $M$. populorum has acquired a unique set of genes via horizontal gene transfer (HGT) that are important to its ability to attack woody hosts. Population genomic analyses of $89 \mathrm{M}$. populorum samples from across its distribution range yielded over 1M SNPs and highlight an unusually high and uneven level of diversity even in recently introduced populations. The patterns suggest both extensive migration and possibly additional unsampled ghost populations. We discovered that a jump to $P$. balsamifera could be driving speciation by imposing selection at the MAT locus, causing a shift from sexual to asexual reproduction, followed by isolation and drift. These results highlight very dynamic mechanisms leading to host colonization and incipient speciation and specialization in this tree pathogen.

Recombination hot spots in the genome of the wheat pathogen Zymoseptoria tritici

E. H. STUKENBROCK (1), J. Grandaubert (1), J. Y. Dutheil (1)

(1) Max Planck Institute for Evolutionary Biology, Ploen, Germany

Phytopathology 105(Suppl. 4):S4.172

Antagonistic co-evolution between pathogens and their hosts can drive rapid adaptive changes in both partners. We aim to understand the underlying mechanisms driving rapid adaptation in two closely related fungal plant pathogens Zymoseptoria tritici (wheat pathogen) and Z. ardabiliae (wild grass pathogen). We previously showed a significantly higher effective population size in $Z$. tritici in spite of strong directional selection pressure imposed to the pathogen in the wheat field. Also we showed a strong impact of natural selection on genome evolution in Z. tritici. A high efficacy of selection may be mediated by recombination. We applied a population genomics approach to infer genome-wide recombination maps in $Z$. tritici and $Z$. ardabiliae. Comparing mean recombination rates of coding and non-coding sequences, we find significantly higher recombination rates in coding sequences implying a central role of recombination in gene evolution. Some genes are located in recombination hotspots further supporting a central role of recombination in gene evolution. In both species recombination rate varies across chromosomes. We correlated recombination maps in the syntenic genomes of $Z$. tritici and $Z$. ardabiliae. Some regions have conserved patterns of recombination while others show highly different patterns. We conclude that patterns of recombination rate evolve in Zymoseptoria allowing orthologous genes to evolve at highly different rates in $Z$. tritici and Z. ardabiliae.

Pitfalls and potential of population genomics

J. F. Tabima (1), B. J. Knaus (1), N. J. GRUNWALD (2)

(1) Oregon State University, Corvallis, OR, U.S.A.; (2) USDA ARS, Corvallis, OR, U.S.A.

Phytopathology 105(Suppl. 4):S4.172

Phytophthora pathogens continue to emerge threatening our agricultural and forest systems. New computational and sequencing approaches allow genomewide characterization of divergence and demographic history in plant pathogen populations. We evaluated a range of approaches including whole genome sequencing, genotyping-by-sequencing (GBS) and Sanger sequencing to infer patterns and processes in the genus Phytophthora. Our experience in calling SNPs revealed that SNP callers (i.e. FreeBayes, SAMtools, GATK and tassel) significantly affected SNP recovery. Furthermore, average read depth needed to be carefully considered during experimental design and implementation. We recommend a strategy, advocated elsewhere, employing a variant discovery phase followed by a variant calling phase, which have goals of high coverage and lower coverage, respectively. While GBS provides huge advantages in terms of cost per SNP and deep SNP coverage across the whole genome, the considerable time investments required to apply sophisticated bioinformatic analysis cannot be ignored. Whole genome sequencing is equally challenging, particularly when applied to hybrids or a population where ploidy varies given difficulties of haplotype phasing. Population genomic approaches combined with high throughput sequencing technologies have the potential to provide novel and unprecedented insights into the emergence of Phytophthora pathogens.

\section{Phytobiome-Plant Interactions: Bridging Phytobiome Structure and Function}

\section{Plants, living with their phytobiomes \\ J. TIEDJE (1) \\ (1) Michigan State University, East Lansing, MI, U.S.A. \\ Phytopathology 105(Suppl. 4):S4.172}

Plants, like all eukaryotic organisms have evolved in a milieu with the preceding prokaryote organisms, and as such have developed to live in concert as well as used the preceding organisms if they provided a competitive advantage. In the few short years of the microbiome we have seen the discovery of a number of features that our (human) microbiome contributes to our health. Would we expect less from the plant microbiome? That is unknown but there are likely more beneficial relationships with plant hosts than now recognized. We have used metagenomics to investigate the plant microbiome in several ways. First, we have used shotgun sequencing of the close rhizosphere of three biofuel crops: corn, switchgrass and Miscanthus to examine its composition at the organism and gene levels. Both show that the corn system is more variable among replicates and different for the two grasses but the later two are different from each other. We have also used a new gene targeted assembly tool, Xander, to assemble genes of interest that is more sensitive than general assembly to describe the N-cycle genes and their likely host bacteria. Second, we have used gene-targeted metagenomics (amplicon sequencing) to assess the nitrogen reductase (nifH) gene in different plant parts. Finally, we have used metatranscriptomics of the rhizosphere of the biofuel crops it investigate which populations and genes are active in this niche.
The grape endophytic microbiome and its impact on Pierce's disease development

P. E. ROLSHAUSEN (1), J. I. Yang (2), P. Ruegger (1), J. Borneman (1), C. Roper (1)

(1) University of California, Riverside, CA, U.S.A.; (2) National Taiwan University, Taipei, CA, Taiwan

Phytopathology 105(Suppl. 4):S4.172

Pierce's Disease (PD) of grapevine, caused by Xylella fastidiosa $(X f)$, poses a major threat to the grape industry. Interestingly, in vineyards that are heavily infected with PD, there are examples of vines exhibiting either no symptoms or very mild PD symptoms (disease-escaped). All vines in a vineyard are clonal so the differences in tolerance to PD are likely not attributed to the genetics of the plant. We hypothesize that the xylem-inhabiting microorganisms in these disease-escaped vines are inhibiting $X f$ and reducing disease severity, due to their shared ecological niche. The goal of this project is to characterize the microbial communities residing in PD-infected vines and compare them to disease-escaped vines to identify beneficial organisms antagonistic to $X f$. Fungal and bacterial endophytic communities were characterized using an Illumina MiSeq platform targeting the ITS and 16S rRNA genes, respectively. Pseudomonadales was the most abundant bacterial taxonomic group, and Pleosporales and Sordariales were the most abundant fungal taxonomic groups. Some phylotypes correlated either positively or negatively with PD severity. Furthermore, we identified a subset of culturable microbes that possessed strong anti- $X f$ properties and suppressed PD symptom development in greenhouse bioassays. We envision harnessing these microbes to construct a beneficial synthetic phytobiome that can be deployed into grapevines trees during the nursery propagation process. 
Plant determinants of root microbiome composition

S. LEBEIS (1), S. Herrera Paredes (2), D. Lundberg (3), J. Dangl (2)

(1) University of Tennessee, Knoxville, TN, U.S.A.; (2) University of North Carolina, Chapel Hill, NC, U.S.A.; (3) Max Planck Institute, Tubebingen, Germany

Phytopathology 105(Suppl. 4):S4.173

While soils are diverse microbial environments, only select and consistent sets of microbial taxa colonize within the endophytic compartment (EC) of root tissue, suggesting microbes in the EC pass through several levels of selection. Massive parallel sequencing of the $16 \mathrm{~S}$ rRNA gene to profile root-associated bacterial communities of a number of Arabidopsis thaliana mutants allowed characterization of multiple selection mechanisms used by the plant immune system to influence EC microbiome. Specifically, the EC root microbiome of plants lacking specific pattern recognition receptors (PRRs) or NOD-like receptor (NLR) signaling components indicated that microbial perception is important for limiting EC bacterial colonization. In a parallel survey with $A$. thaliana mutants in defense phytohormone biosynthesis and/or downstream signaling, we discovered that SA in particular plays a significant role in EC microbiome membership. These findings were confirmed when wildtype and mutant plants were inoculated with a well-defined mixture of bacterial root isolates and treated half of the plants with exogenous SA, allowing us to untangle direct SA effects from plant-dependent effects on bacterial communities. Together, these studies describe specific functions of multiple components of the plant immune system to shape EC microbiome composition, offering an exciting new context for how plant immunity promotes homeostasis and health.

\section{Oomycete community diversity: The soybean root rot complex}

A. ROJAS (1), J. L. Jacobs (1), C. A. Bradley (2), D. M. Malvick (3), B. D. Nelson (4), A. Robertson (5), A. U. Tenuta (6), K. A. Wise (7), L. Giesler (8), D. Jardine (9), J. Rupe (10), M. I. Chilvers (1)

(1) Michigan State University, East Lansing, MI, U.S.A.; (2) University of Illinois, Urbana, IL, U.S.A.; (3) University of Minnesota, St. Paul, MN, U.S.A.; (4) Department of Plant Pathology, North Dakota State University, Fargo, ND, U.S.A.; (5) Iowa State University, Ames, IA, U.S.A.; (6) Ontario Ministry of Agriculture Food and Rural Affairs, Ridgetown, ON, Canada; (7) Purdue University, West Lafayette, IN, U.S.A.; (8) University of NebraskaLincoln, Lincoln, NE, U.S.A.; (9) Kansas State University, Manhattan, KS, U.S.A.; (10) University of Nebraska, Fayetteville, AR, U.S.A.

\section{Phytopathology 105(Suppl. 4):S4.173}

The root and surrounding rhizosphere ecosystem is a dynamic and complex environment subject to the interaction of different microbial communities, which affect the outcome of the plant-phytobiome. In the root ecosystem, oomycetes are part of the microbial community and are some of the most aggressive and important plant pathogens. In the United States, soybeans are produced across 76 million acres of highly productive land, but can be severely impacted by diseases caused by oomycetes. We initially utilized a two-year culture based survey to study oomycetes associated with soybean seedlings from across 11 states in the Midwest, characterizing the communities and profiling phenotypic traits such as pathogenicity and aggressiveness. With this approach a total of 83 different oomycete species were identified and characterized. The survey served as a basis to develop markers and phenotypic data that could be used to further investigate and characterize oomycete communities associated with agricultural systems. We are currently utilizing this phenotype information and amplicon-based community analysis to evaluate the role of climatic, edaphic and biotic factors on the oomycete community structure. Improved understanding of the phytobiome, especially in the root system, and the factors that influence it will enable improved disease management and enhance plant health.

Local and systemic bacterial colonization of germ-free plants with synthetic microbial communities of the Arabidopsis microbiota

Y. BAI (1), G. Srinivas (1), D. B. Mueller (2), J. Vorholt (2), P. SchulzeLefert (1)

(1) Max Planck Inst Zuchtungsforschung, Cologne, Germany; (2) ETH, Zurich, Switzerland

Phytopathology 105(Suppl. 4):S4.173

Culture independent $16 \mathrm{~S}$ rRNA gene profiling recently revealed distinctive Arabidopsis-associated bacterial communities in roots (Bulgarelli et al., 2012; Lundberg et al., 2012) and leaves (Vorholt et al., 2012). The availability of comprehensive pure cultures of root- and leaf-derived bacteria is critical to deeply understand colonization ability and organ specificity of Arabidopsisassociated bacteria. We have established a reference culture collection of pure bacteria stains-Proteobacteria, Actinobacteria, Bacteroidetes, and Firmicutes-from Arabidopsis thaliana grown in nature soil, representing $60 \%$ root- and $50 \%$ leaf-associated bacterial communities detected by $16 \mathrm{~S}$ pyrosequencing. With the culture collection, we colonized Arabidopsis thaliana with different synthetic communities (SynComs) to assess their potential of colonization and competition in our gnotobiotic model system. We found that host-independent mechanisms dominated the bacteria community shift from input to output. All output communities were robust against changes of 4-fold relative abundance of Proteobacteria to bacteria in other phylum from input community. A subgroup of root- or leaf-derived bacteria successfully colonized both roots and leaves. Interestingly, clay inoculation of leaf-derived SynCom with root- and soil-derived SynCom led much less phyllosphere colonization than spray inoculation of leaf-derived SynCom, indicating that the majority of leaf-derived SynCom is not competitive in the clay environment and needs direct contact to successfully colonize phyllosphere.

\section{Seed Transmission of Vector-Borne Pathogens: Mysteries, Caveats, and Mechanisms}

\author{
The impact of bacterial and viral diseases in hybrid seed production: The \\ human factor \\ C. J. KUROWSKI (1) \\ (1) Monsanto Company, Woodland, CA, U.S.A. \\ Phytopathology 105(Suppl. 4):S4.173
}

Insects are the most common vectors of bacterial and viral pathogens. Bacterial and viral pathogens are the most prevalent seed-borne and seedtransmitted pathogens encountered by the vegetable seed industry, complicating the management of the diseases they cause. Historically, in the literature seed has been implicated as a pathway for many plant pathogens, and in the further spread of the diseases they cause. While some of these claims are supported by strong scientific evidence, others are not. Such unsupported claims have major cost and time ramifications for the seed industry. Worldwide movement of commercial seed is impeded by countries that use these unsubstantiated claims to mandate unwarranted seed health testing. New and existing diagnostic methods are used for seed testing, at times without proper validation, which can lead to erroneous conclusions. The criteria for a rigorous and effective seed health test, as well as why seed health testing has not moved away from traditional techniques in favor of the more sensitive molecular techniques will be discussed from an industry perspective. Currently, a zero tolerance threshold is imposed for many seed-borne pathogens, which may not be attainable, nor may such a goal be reasonable or necessary. In an effort to address unsupported seed-borne/transmission claims, the vegetable seed industry, in collaboration with the International Seed Federation, is developing science-based, pest lists for vegetable crops.

Introduction and overview of viruses seed-transmitted and nonpersistently transmitted by aphids

S. A. TOLIN (1)

(1) Virginia Polytechnic Institute and State University, Blacksburg, VA, U.S.A. Phytopathology 105(Suppl. 4):S4.173

The number of viruses known to be transmitted vertically from seeds to seedlings has increased to over 200, and is dominated by about 30 members of the Potyvirus genus, with a few viruses in the Bromoviridae (Alfalfa mosaic virus, Cucumber mosaic virus, and Peanut stunt virus), Fabavirus, and Carlavirus. These viruses and potyviruses are also transmitted horizontally by aphids in a non-persistently or stylet-borne manner. Transmission of filamentous potyviruses is known to be mediated by interaction between specific motifs of two viral-encoded proteins, HCPro and CP, which function in attachment and release of virus particles from stylet tips. About half of the potyviruses infect and are seed-transmitted in legumes in the family Fabaceae, with up to three viruses infecting each of six other dicot families (Asteraceae, Brassicaceae, Caricaceae, Cucurbitaceae, Rosaceae, Solonaceae) and two monocot families (Amaryllidaceae, Poaceae). Aphids of both colonizing and non-colonizing species of host plants can usually transmit each virus, with varying efficiency. Efforts to understand pollen, ovule, and embryo infection, and manage these seed-borne viruses, will be discussed for important pathogens of lettuce and legume crops. New approaches to confirm 
vertical and horizontal transmission of Zucchini yellow mosaic virus, an emerging disease of cucurbits spread globally via infected seed, and to reveal significant genome diversity, will be discussed.

Detection methods for Candidatus Liberibacter, and the threat of transmission in true seed and vegetatively propagated plant parts

J. K. BROWN (1)

(1) The University of Arizona, Tucson, AZ, U.S.A.

Phytopathology 105(Suppl. 4):S4.174

Candidatus Liberibacter is a recently recognized genus of mostly unculturable bacteria pathogens that infect plants and their psyllid vector. They cause diseases of carrot, celery, citrus, and solanaceous crop species. Although many free-living plant bacterial pathogens are seed borne or distributed through vegetative planting materials, seed transmission of insect vectortransmitted bacterial plant pathogens are uncommon. Liberibacter species can be circulative and propagative and further, may also be transovarially- and sexually-transmitted in the vector, making transmission through true seed a conundrum because it is not intuitive how having so many different transmission pathways could enhance survival without reducing fitness. Diagnostic studies have implicated Liberibacter transmission to plant- and seed-parts of herbaceous and woody plants inoculated using the psyllid vector, grafting, or dodder. Detection of Liberibacter in true seed and/or in vegetative parts from infected plants has been determined using electron microscopy, and serological and molecular detection platforms. The best-studied species are the L. asiaticus pathogen of citrus, and L. solanacearum that infects carrot, celery, potato, and tomato, making them ideal systems for assessment. In the above contexts, the implications of requirements for testing true seed- and/or vegetatively propagated parts for Liberibacter infection, recently imposed by certain countries, will be addressed.

Survey of diagnostic tools for detection of viroids and impacts of test results on the seed industry

R. W. HAMMOND (1)

(1) USDA ARS NEA MPPL, Beltsville, MD, U.S.A

Phytopathology 105(Suppl. 4):S4.174

Viroids are unencapsidated, single-stranded, covalently closed circular, highly structured noncoding RNAs of 239 - 401 nucleotides that are replicated by host enzymes and cause disease in several economically important crop plants. Although viroids are primarily and easily transmitted mechanically through contact with contaminated pruning tools, by human hands, and by contact between plants, they are also spread vegetatively by graft inoculation, cuttings, micro-plants and tuber propagation, and in some cases, by insects. Pospiviroids (type member Potato spindle tuber viroid, PSTVd) are also transmitted through infected pollen and seed at variable rates, and seed transmission has recently been shown to contribute to the international interception of several pospiviroid species. Seed certification programs, which rely on sensitive diagnostic and detection methods and quarantine enforcement, have resulted in effective control of several diseases caused by viroids, eg. resulting in the eradication of PSTVd from potato in North America. This presentation will attempt to provide a critical examination of the evidence for seed transmission of viroids and its role in the epidemiology of pospiviroid infections in vegetable crops, methods used and limitations for detection of viroids in seeds, and implications for the seed industry and growers

Role of seed transmission in the spread of maize lethal necrosis in East Africa

M. G. REDINBAUGH (1)

(1) USDA, ARS Corn Soybean and Wheat Quality Research and Ohio State University, Wooster, OH, U.S.A.

Phytopathology 105(Suppl. 4):S4.174

Maize is a staple food in sub-Saharan Africa, where pest and disease outbreaks reduce food security for smallholder farming communities. In September 2011, an outbreak of maize lethal necrosis (MLN) was reported on maize in Kenya that caused major lossesfor farmers. The disease was caused by co-infection of maize with Maize chlorotic mottle virus (MCMV) and Sugarcane mosaic virus (SCMV), and has since found in Rwanda, Tanzania, the Democratic Republic of Congo, Uganda, South Sudan, and Ethiopia. Since SCMV has been known in the region for at least 30 years, the MLN outbreak was linked primarily to the emergence of MCMV, which was not previously known in Africa. Vectors of MCMV, especially maize thrips (Frankliniella williamsi), are present in all parts of the region where MLN has been found. However, the emergence of MLN across a very large region in the span of a few years, the detection of MCMV on maize seed from the region and previous research indicating a potential for virus transmission through have led to speculation that seed transmission of MCMV played a large role in MLN emergence in East Africa. Current methods for assessing virus transmission through seed will be discussed in relationship to their utility in defining the rates of MCMV transmission from seed of maize hybrids and cultivars grown in East Africa, and in preventing inadvertent spread of the virus through seed.

\section{Molecular/Cellular/Plant-Microbe Interactions}

\section{APS-CSPP Joint Symposium on Plant Pathology and Disease Control}

\section{Engineered nucleases to combat virus infections}

S. P. DINESH-KUMAR (1), V. Fondong (2), D. Segal (3), B. Chan (1), E. Park (1)

(1) University of California, Department of Plant Biology and The Genome Center, College of Biological Sciences, Davis, CA, U.S.A.; (2) Delaware State University, Department of Biological Sciences, Dover, DE, U.S.A.; (3) University of California, Department of Biochemistry and Molecular Medicine and The Genome Center, Davis, CA, U.S.A.

Phytopathology 105(Suppl. 4):S4.174

Cassava is the third most important crop in tropical Africa and is a staple food to more than 500 million people worldwide, most of whom live in subSaharan Africa. However, successful production of cassava is threatened by several cassava mosaic geminiviruses (CMGs) that cause cassava mosaic disease (CMD) resulting in an annual crop loss of US\$1.9-2.7 billion. We will present our progress on custom engineering of CRISPR-Cas9 (Clustered Regularly Interspaced Short Palindromic Repeats/CRISPR-associated) that target and cleave CMG DNA sequences that are both conserved across multiple CMG isolates and critical for CMG virulence. The efficacy of designer CRISPR-Cas9 for viral disease control will be discussed.

\section{The resistance mechanisms of Fusarium graminearum to fungicides \\ Z. MA (1) \\ (1) Zhejiang University, Hangzhou, China \\ Phytopathology 105(Suppl. 4):S4.174}

Fusarium head blight (FHB) caused by $F$. graminearum (Fg) and several other Fusarium spp. is a devastating disease of cereal crops which can cause huge losses in epidemic years. In addition to the yield loss caused by the disease, the contamination of infected grains with mycotoxins poses a serious threat to human and animal health. Despite the high economic impact of FHB, efficient strategies for the management of FHB have not been well developed. One primary method for management of FHB is through the application of fungicides during wheat anthesis, the time of primary infection. Thus, in this presentation, I will review some of our recent advances in i) monitoring fungicide resistance in Fg in China; ii) resistance mechanisms of Fg to several major classes of fungicides including benzimidazoles, demethylation inhibitors, and a novel compound JS399-19. It is very interesting that JS39919 shows highly inhibitory activity towards some Fusarium species, but not to other fungi. To explore the mode of action of this species-specific compound, we conducted a whole-genome transcript profiling together with genetic and biochemical assays, and discovered for the first time that JS399-19 targets the Fg myosin I protein. Point mutations in Fg myosin I is responsible for the resistance of $\mathrm{Fg}$ to JS399-19. Finally, I will discuss the strategy for management of fungicide resistance in FHB.

The plant Mediator co-activator complex as an integrative hub for transcriptional regulation of jasmonate-signaled plant immunity

C. LI (1)

(1) Institute of Genetics and Developmental Biology, Chinese Academy of Sciences, Beijing, China

Phytopathology 105(Suppl. 4):S4.174

A major progress in our understanding of the jasmonate signaling is that the perception of the active hormone by the E3 ubiquitin ligase SCFCOI1 is tightly linked to genome-wide transcriptional reprogramming that is regulated by the master transcription factor MYC2. However, it remains unclear how the jasmonate receptor transmits regulatory information to RNA polymerase II 
to specifically transcribe jasmonate-responsive genes. Here we report that the MED25 subunit of the Arabidopsis Mediator provides an interface for interactions of COI1, MYC2 and the histone acetyltransferase HAC1 at the core promoters of MYC2 targets. Our results unravel a mechanism of how Mediator channels hormone-specific regulatory signals to the Pol II general transcription machinery and highlight the ability of Mediator in coordinating gene expression programs of diverse signaling pathways.

\section{Aflatoxin production and environmental oxidative stress in Aspergillus} flavus: Implications for host resistance

J. C. FOUNTAIN (1), L. Yang (1), P. Khera (2), R. C. Kemerait (1), R. D. Lee (1), B. T. Scully (3), R. K. Varshney (2), B. Guo (4)

(1) University of Georgia, Tifton, GA, U.S.A.; (2) International Crop Research Institute for the Semi Arid Tropics, Hyderabad, India; (3) USDAARS, Fort Pierce, FL, U.S.A.; (4) USDA-ARS, Tifton, GA, U.S.A.

Phytopathology 105(Suppl. 4):S4.175

Aflatoxin is of major concern in global food security. Host resistance to aflatoxin is negatively influenced by environmental stress. Given that reactive oxygen species (ROS) accumulate in host tissues during abiotic stress, and exacerbate aflatoxin production in Aspergillus spp. in vitro, it has been hypothesized that ROS may serve as signals between $A$. flavus and its hosts. In order to determine the potential functions of aflatoxin production in oxidative responses, we compared the responses of five toxigenic and five atoxigenic isolates of $A$. flavus and A. parasiticus to $\mathrm{H}_{2} \mathrm{O}_{2}$ induced oxidative stress over a gradient ranging from $0-50 \mathrm{mM}$ in toxin-conducive and nonconducive media. There was variability among isolates with regard to their degree of oxidative stress tolerance with toxigenic isolates generally exhibiting greater levels of tolerance with highly virulent toxigenic isolates (A9, AF13, and Tox4) and well performing atoxigenic biocontrol isolates (AF36, Aflaguard, and K49) surviving the greatest levels of stress within their respective groups. To explain the functional differences between these isolates, we also performed transcriptomic and biochemical analyses examining the oxidative responses of the isolates with respect to their ability to produce aflatoxin. In application, identifying the causes of variation in oxidative stress tolerance among atoxigenic isolates may allow for prediction of their performance as biocontrols in field applications.

Identification of disease resistance genes for enhancement of existing potato cultivars

D. HALTERMAN (1)

(1) USDA/ARS Vegetable Crops Research Unit, Madison, WI, U.S.A. Phytopathology 105(Suppl. 4):S4.175

A plant's ability to defend itself against host-specific microbes is specified by disease resistance $(R)$ genes. Upon recognition of an invading pathogen, $\mathrm{R}$ proteins are responsible for the activation of a multitude of responses ultimately leading to resistance. The majority of $R$ genes are dominant and can be identified using germplasm screening techniques. Genes that condition resistance to many economically important potato diseases, such as Phytophthora infestans, Verticllium dahliae, and Potato Virus Y, have been identified. Genetic markers closely associated with $R$ genes are useful for breeding new cultivars with increased resistance. Equally useful is the identification and isolation of the $R$ genes for use in characterization of the resistance response, precision marker development, and stable incorporation of the genes into existing popular cultivars. This talk will include recent research results that are being directed towards the identification of major $R$ genes and the prospects for their utilization in potato breeding.
Progresses on pathogenesis and control of the rice false smut pathogen Ustilaginoidea virens

W. SUN (1), A. Fang (1), Y. Han (1), K. Zhang (1), Y. Zhang (1), N. Zhang (1), M. Wang (1)

(1) China Agricultural University, Beijing, China

Phytopathology 105(Suppl. 4):S4.175

Ustilaginoidea virens is an ascomycetous fungus that causes rice false smut, an emerging disease around the world. The disease causes significant grain yield and quality loss in rice. Despite economic impact of the disease, little is known about the pathogenicity of $U$. virens. Through genome analyses, we revealed that the pathogen has a less extensive polysaccharide degradation machinery, particularly no pectin lyases, and thus minimizes the induction of host immunity by restricting the release of cell wall fragments, which is a typical feature for biotrophic pathogens. In addition, the pathogen possesses reduced gene inventories for nutrient uptake and secondary metabolism, which may result from adaptations to the specific floret infection. Evolutionarily, U. virens is close to the entomopathogenic Metarhizium spp., suggesting potential host jumping across kingdoms. Transcriptome analyses indicate that a specific set of genes for secreted proteins and secondary metabolism play important roles in virulence and pathogenicity of $U$. virens. Furthermore, eight candidate effectors were experimentally demonstrated to induce hypersensitive responses in Nicotiana benthamiana. And 18 effectors were found to suppress plant innate immunity in $N$. benthamiana and in rice. Together, these results offer new insights into molecular mechanisms of evolution, biotrophy and pathogenesis of $U$. virens. Some strategies for disease management are also discussed.

A novel tobacco RING E3 ligase NtRFP1 attenuates symptoms induced by a geminivirus-encoded $\beta C 1$ via mediating the ubiquitination and degradation of $\beta C 1$

Q. Shen (1), M. Bao (1), L. Cao (1), T. Hu (1), H. Zhang (2), C. Huang (1), X. Yang (3), F. Song (1), Q. Xie (2), X. ZHOU (3)

(1) State Key Laboratory of Rice Biology, Institute of Biotechnology, Zhejiang University, Hangzhou, China; (2) State Key Laboratory of Plant Genomics, National Center for Plant Gene Research, Institute of Genetics and Developmental Biology, Chinese Academy of Sciences, Beijing, China; (3) State Key Laboratory of Rice Biology, Institute of Biotechnology, Zhejiang University; State Key Laboratory for Biology of Plant Diseases and Insect Pests, Institute of Plant Protection, Chinese Academy of Agricultural Sciences, Beijing, China

Phytopathology 105(Suppl. 4):S4.175

The $\beta C 1$ protein of Tomato yellow leaf curl China virus associated betasatellite functions as a pathogenicity determinant. To better understand the molecular basis whereby $\beta \mathrm{C} 1$ functions in pathogenicity, a yeast two-hybrid screen of a tobacco cDNA library was carried out using $\beta C 1$ as bait. The screen revealed that $\beta C 1$ interacts with a tobacco RING-finger protein designated NtRFP1, and the interaction was confirmed using a bimolecular fluorescence complementation assay in Nicotiana benthamiana cells. NtRFPI expression was induced by $\beta \mathrm{C} 1$, and in vitro ubiquitination assays showed that NtRFP1 is a functional E3 ubiquitin ligase that mediates $\beta \mathrm{C} 1$ ubiquitination. In addition, $\beta \mathrm{C} 1$ was shown to be ubiquitinated in vivo and degraded by the plant $26 \mathrm{~S}$ proteasome. After viral infection, plants overexpressing NtRFP1 developed attenuated symptoms, and plants silenced for NtRFP1 expression had severe symptoms. Other lines of evidence showed that NtRFP1 attenuates $\beta C 1$ symptoms by promoting $\beta C 1$ degradation by the $26 \mathrm{~S}$ proteasome. These results demonstrate that NtRFP1 is an important component of plant defense responses to geminiviruses, and support a model whereby the tobacco RING E3 ligase NtRFP1 attenuates disease symptoms by interacting with $\beta C 1$ to mediate its ubiquitination and degradation via the ubiquitin/26S proteasome system.

\section{Impact of Repeat Elements on Genome Evolution and Pathogen Biology}

Repetitive DNA and effectors in the compartmentalized genomes of Fusarium oxysporum species complex

P. Travers (1), Y. Zhang (1), L. J. MA (1)

(1) University of Massachusetts Amherst, Amherst, MA, U.S.A.

Phytopathology 105(Suppl. 4):S4.175

Fusarium oxysporum species complex causes highly destructive Fusarium wilts in nearly all agriculturally important plants. In addition, some $F$. oxysporum strains can cause life-threatening infections in immunocompromised patients. An interesting point about $F$. oxysporum is that any pathogenic form exhibits high host specificity. Comparative genomics demonstrated that horizontal transfer of pathogenicity chromosomes conveys host-specific pathogenicity (Ma et al., 2010). With an overall objective to understand the correlation between genome dynamics and the evolving pathogenicity, this study compared the copy number variation of transposable elements among different pathogenic Fusarium genomes. We will describe methods we developed to survey copy numbers of transposable elements in $F$. oxysporum species complex using next-gen sequencing. The correlation of the expansion of certain transposable elements and the evolution of specific pathotypes will be discussed. 
Comparative genome analysis of members of Magnaporthaceae sheds light on pathogenesis

L. H. Okagaki (1), J. K. Salisbury (1), T. John (1), B. Clay (1), Y. Oh (1), R. A. DEAN (1)

(1) Center for Integrated Fungal Research, North Carolina State University, Raleigh, NC, U.S.A.

Phytopathology 105(Suppl. 4):S4.176

Magnaporthaceae is a family of ascomycetes that includes three fungi of great economic importance: Magnaporthe oryzae, Gaeumannomyces graminis var. tritici, and Magnaporthe poae. These three fungi cause widespread disease and loss in cereal and grass crops including rice blast disease (M. oryzae), take-all disease in wheat and other grasses ( $G$. graminis), and summer patch disease in turf grasses (M. poae). We conducted a genome-scale comparative study across 40 fungal genomes (Broad Institute) to identify orthologous groups unique to the three Magnaporthaceae species. Gene Ontology annotation, Interpro protein domain identification, and Meme protein motif examination were used to identify potential orthologous group functions that may shed light on Magnaporthaceae pathogenesis. In addition, we performed refined genome annotation, syntenic sequence alignment, gene expression, repetitive sequence and protein homology analyses. We found that $M$. poae and $G$. graminis are more closely related than to $M$. oryzae, sharing a higher number of homologs, more conserved gene function, and larger syntenic regions. Among a core set of genes, many but not all apparent orthologs expressed similar patterns of gene expression. Differences in the type and frequency of repetitive elements were observed. Relationships between repetitive elements and ortholog diversity of neighboring genes will be discussed.

Repeats, RIPping and genome evolution in Mycosphaerella graminicola (Zymoseptoria tritici), the cause of septoria tritici blotch of wheat

S. B. GOODWIN (1)

(1) USDA-ARS / Purdue University, West Lafayette, IN, U.S.A.

Phytopathology 105(Suppl. 4):S4.176

Mycosphaerella graminicola (synonym Zymoseptoria tritici) causes septoria tritici blotch, one of the most common and economically important diseases of wheat worldwide. The finished genome sequence of this ascomycete was at least $17 \%$ repetitive, $70 \%$ of which was composed of retrotransposons. All copies of a DNA cytosine methyltransferase gene were located in subtelomeres, except for one on chromosome 6 which appeared to represent the original sequence based on synteny with related species. All copies of this gene including the putative original showed signatures of repeat-induced point mutation (RIP), a mechanism in fungi for inactivating transposons. These mutations led to premature stop codons in the gene sequence. A genome-wide methylation assay showed that $M$. graminicola lacks cytosine methylation, so all copies of the gene including the original appear to be inactivated. In contrast, a single, un-mutated copy of the DNA methyl transferase was present in 11 other species, and those tested all had cytosine methylation, including two close relatives of $M$. graminicola that are thought to have diverged within the past 10,500 years. Therefore, recent amplification of a single-copy gene appears to have made all copies including the original visible to the RIP machinery, resulting in a loss of cytosine methylation in the genome of $M$. graminicola. This may be the first example of a previously single-copy gene that has been amplified and rapidly inactivated in a fungus.

Effector diversification within compartments of the Leptosphaeria maculans genome

T. ROUXEL (1), M. H. Balesdent (1), J. Grandaubert (1)

(1) INRA, Thiverval-Grignon, France

Phytopathology 105(Suppl. 4):S4.176

Transposable Elements (TEs) have been considered for long as "junk" DNA in the genome of complex eukaryotes. However, massive sequencing efforts coupled with phylogenetic analyses suggest TEs can act as genome shapers and be a source of gene innovation and genome plasticity, eventually contributing to genome divergence. Fungi are simple and easy to manipulate eukaryote organisms, for which the ever-growing genome information indicates that many plant-associated fungi have a tendency towards genome size expansion. This increase in genome size is mostly driven by TE expansion that eventually shapes adaptive regions of the genome. Such genome regions host genes involved in niche adaptation and favor accelerated evolutionary dynamics of these genes. Focusing on the Leptosphaeria maculansLeptosphaeria biglobosa species complex of closely related plant pathogenic fungi, I will discuss the link between TE invasion/TE bursts in genomes and (i) speciation, (ii) the rise of two-speed genomes, shaping plastic genome environments, (iii) gene diversification that contributed to adaptation to new hosts, (iv) heterochromatine-based regulation of expression of effector genes, (v) accelerated adaptation to resistance gene pressure in gene-for-gene systems.

Repetitive elements, architects of genomic variation in Verticillium K. F. DOBINSON (1), S. J. Klosterman (2), A. Anchieta (2), Z. Li (3), S. Amyotte (4), L. J. Ma (5)

(1) Dept. of Biology, University of Western Ontario, London, ON, Canada; (2) USDA-ARS, Salinas, CA, U.S.A.; (3) State Key Laboratory of Cotton Biology, Cotton Research Institute, Anyang Henan, China; (4) Phirelight Security Solutions Inc., Ottawa, ON, Canada; (5) Dept. of Microbiology \& Molecular Biology, University of Massachusetts-Amherst, Amherst, MA, U.S.A.

Phytopathology 105(Suppl. 4):S4.176

Vascular wilt pathogens in the genus Verticillium show considerable variation with respect to their host ranges, genomic organization, and the variety and number of transposable elements (TEs) that they carry. These families of TE sequences were first documented in the wide host range, plant pathogenic species $V$. dahliae. They have since been shown in $V$. dahliae to comprise a small number of class I elements (retrotransposons), and relatively larger numbers of genetically diverse class II elements (DNA transposons). Subsequent analysis and use of these sequences in Verticillium research have contributed much to our knowledge of this genus, and particularly of $V$. dahliae. The TEs are involved not only in sequence transposition, but are also associated with insertions and deletion of genetic material, and consequent inter-and intra-chromosomal rearrangements. Such events have the potential to effect the changes in genome content and structure that have been hypothesized to drive genetic adaptation of $V$. dahliae to new hosts.

\section{Professionalism/Outreach}

\section{5th I. E. Melhus Graduate Student Symposium-From Local to Global: New Developments in Disease Risk Prediction and Crop Loss Assessment}

Understanding antibiotic resistance in Erwinia amylovora: Impacts on disease management and epiphytic bacterial populations in apple orchards

K. A. BEKOSCKE (1), K. D. Cox (1)

(1) Cornell University, Geneva, NY, U.S.A.

Phytopathology 105(Suppl. 4):S4.176

Streptomycin applications are essential for the control fire blight in New York. Recent development of streptomycin resistance in New York strains of E. amylovora poses an immense challenge for future disease management. Our goals were to (1) investigate the diversity of New York strains of streptomycin resistant (SmR) and streptomycin sensitive $(\mathrm{SmS})$ E. amylovora to determine the status and origin of SmR E. amylovora, and 2) investigate how increasing applications of streptomycin and kasugamycin directly affect epiphytic bacterial populations in the apple phyllosphere. Amplification and sequencing of CRISPR region DNA was used to examine E. amylovora strain diversity in New York and to compare NY E. amylovora strains with SmR E. amylovora from other locations world-wide. Results have provided evidence for the likely introduction of SmR strains from other areas into NY and also for resistance development within NY orchards. Field trials conducted with increasing antibiotic applications followed by identification and enumeration of epiphytic bacteria from treated apple leaves were used to elucidate the effects of antibiotics on bacterial populations. Results have shown that increased applications of both streptomycin and kasugamycin have a significant impact on community structure and population size of epiphytic bacteria in the apple phyllosphere.

Epidemiology and control of spinach downy mildew in coastal California R. A. CHOUDHURY (1), S. T. Koike (2), A. Fox (3), K. V. Subbarao (4), S. J. Klosterman (5), N. McRoberts (1)

(1) University of California, Davis, CA, U.S.A.; (2) Cooperative Extension Monterey County, Salinas, CA, U.S.A.; (3) Fox Weather, LLC, Fortuna, CA, U.S.A.; (4) UC Davis, Davis, CA, U.S.A.; (5) USDA ARS, Salinas, CA, U.S.A.

Phytopathology 105(Suppl. 4):S4.176

The most serious threat to global fresh market spinach production is spinach downy mildew, caused by the obligate biotrophic pathogen, Peronospora 
effusa. Downy mildew causes yellow chlorotic lesions on spinach leaf tissue, often accompanied by abundant sporulation on the undersides of leaves. Very little is known about the environmental parameters that affect spinach downy mildew development and how the pathogen disperses within a growing region. Spore traps linked to a species-specific qPCR assay were set up at four sites throughout the Salinas Valley in 2013 and 2014. Disease ratings were conducted in fields nearby the spore traps to link disease incidence with inoculum levels and weather conditions. Results from the spore trap study suggest there is a periodic nature to the spore density in the air. Disease ratings in the vicinity of traps show a high correlation between disease incidence and airborne spore density. Logistic regression analysis suggested that cool temperatures and high wind result in increased airborne spore density. Commercially available biofungicides were compared for efficacy in field studies. Several products showed activity against downy mildew and may be useful for disease control. Results from a single trial suggested cultivar mixtures did not give disease control sufficient for commercial use.

A three-pronged approach to late blight management; host resistance, diagnostics, and understanding pathogen diversity

Z. R. HANSEN (1), C. D. Smart (2)

(1) Cornell University, Ithaca, NY, U.S.A.; (2) Cornell University, Geneva, NY, U.S.A.

Phytopathology 105(Suppl. 4):S4.177

Phytophthora infestans is a highly aggressive pathogen that causes late blight, one of the most constraining factors in potato and tomato production. Three separate strategies are being explored to improve late blight management. First, 39 tomato varieties were evaluated for late blight resistance in field trials. Varieties with both $P h-2$ and $P h-3$ resistance genes, or were homozygous for $P h-3$ only, along with three heirloom varieties, were highly resistant. In addition to host resistance, three DNA-based pathogen diagnostic assays were developed to enhance pathogen detection and identification. A loop-mediated isothermal amplification (LAMP) assay can detect $P$. infestans after a one hour isothermal reaction. A high-resolution melt analysis assay was also developed to differentiate three $P$. infestans lineages, US-8, US-11, and US-23. The third assay used locked nucleic acid technology to distinguish US-23 from non-US-23 individuals based on two SNPs. Because understanding pathogen diversity is critical to proper management, I am using genotyping-by-sequencing to identify population structure within four $P$. infestans lineages (US-8, US-11, US-23, and US-24). Preliminary results, based on neighbor-joining and principle component analyses, indicate that some isolates collected from the same geographic region in different years show high similarity. This supports the hypothesis that overwintering inoculum is responsible for initiating regional outbreaks.

Epidemiological concepts and methods to predict the effects of plant morphology and partial resistance components on sunflower black stem epidemics

A. A. SCHWANCK (1), S. Savary (1), L. Willocquet (1)

(1) Inst National de la Recherche Agronomique, Toulouse, France

Phytopathology 105(Suppl. 4):S4.177
Experimental, modeling, and statistical approaches may be combined to mobilize epidemiological concepts to assess host plant resistance and its components. A set of 21 sunflower genotypes was used to assess morphological traits (MT) and sunflower black stem intensity (BS; caused by Phoma macdonaldii) in field experiments, as well as disease cycle components in greenhouse (GHE) and controlled conditions (CCE) experiments. The identification of predictors of BS field resistance was based on analyses performed at two scales. First, relationships between MT and BS intensity were analyzed at the field plot scale with a range of methods (cluster analyses of morphological and epidemiological variables, contingency and correspondence analyses, and logistic regressions). Second, predictors for field resistance were identified using genotype-scale data from MT, GH and $\mathrm{CC}$ measurements, using Kendall's tau and $W$ tests, and binary logistic regressions. The first approach showed significant $(P<0.05)$ associations of number of green leaves (GL), plant height $(\mathrm{PH})$ and stem diameter with disease intensity in the field. The second approach showed significant $(P<0.05)$ association between field BS measurements and MT (GL and PH), GHE (stem lesion length and expansion) and CCE (infection efficiency) predictors. CCE predictors were better associated to $\mathrm{BS}$ incidence, and $\mathrm{GH}$ predictors to BS severity. These results point at potential phenotypic markers for partial host plant resistance.

Characterization and distribution of fungi associated with needle defoliation of eastern white pine (Pinus strobus)

S. A. WYKA (1), K. D. Broders (2), I. Munck (3)

(1) University of New Hampshire, Dover, NH, U.S.A.; (2) University of New Hampshire, Durham, NH, U.S.A.; (3) USDA Forest Service, Durham, NH, U.S.A.

Phytopathology 105(Suppl. 4):S4.177

Eastern white pine is a crucial ecological and economic component of forests in the northern United States and eastern Canada and is facing an emerging problem with white pine needle defoliation (WPND). It is unclear whether WPND is caused by one or a combination of multiple fungal pathogens. Therefore, the objective of this study was to characterize the fungi associated with WPND in the Northeast United States. To date 51 species of fungi either cultured from diseased pine needles or from fruiting bodies on pine needles, were identified based on morphology and sequence data. The species most frequently recovered from diseased needles included Lecanosticta acicola (Mycosphaerella dearnessii), a historically southern pine pathogen, and a putative new species closely related to pine pathogen Septorioides pinithunbergii. A multi-gene phylogenetic analysis of this new species placed the fungus in an entirely new genus and family within the Botryosphaeriales. This study also provides the first phylogenetic analysis of Lophophacidium dooksii (Canavirgella banfieldii) and Bifusella linearis, two obligate biotrophic fungi frequently observed on pine needles in the Northeast, for which no sequence data was previously available. As $L$. acicola appears to be the primary pathogen causing WPND, current research is investigating the epidemiology and role of climate on epidemics of WPND, as well as the potential northerly migration of $L$. acicola into northeastern pine populations.

\section{Careers in Industry}

Exploring some of the myths of working in industry P. J. KUHN (1)

(1) Syngenta Crop Protection, Greensboro, NC, U.S.A. Phytopathology 105(Suppl. 4):S4.177

After graduation, three of the main career paths that plant pathologists typically consider are academia (e.g., postdoctoral research, college faculty), public sector (e.g., USDA), and private sector including industry. Of these options, the majority of new graduates are probably least well informed about possibilities in industry. For many, who have either not had or not taken the opportunity of an internship or other temporary period working in an industry setting, views may be founded largely on second hand information, opinion, and anecdote, which can be subjective and misleading. Against this backdrop, it should not be surprising that there are frequent misconceptions or myths about careers in the private sector. Some of the myths that will be explored concern freedom to publish, security of tenure, and the scientific working environment. Based on this presentation and the other contributions to this symposium, it is hoped that new plant pathologists will gain a more informed perspective on which to base decisions as they consider the various career options available to them.

\section{Plant pathology career opportunities in the seed industry}

S. A. ROSENBERGER (1)

(1) Monsanto, Woodland, CA, U.S.A.

Phytopathology 105(Suppl. 4):S4.177

The seed industry is comprised of companies that develop, produce and distribute seed products all over the world for a variety of crops. There are a number of exciting and rewarding career opportunities for plant pathologists in the seed industry. From finding new sources of disease and insect resistance, to conducting product performance and efficacy trials, to defining seed trade policy, plant pathologists play an integral role in seed development, distribution and regulation. Students interested in a career in industry will need to actively apply technical knowledge and skills gained in graduate school to create and deliver products that address grower needs. In addition, individuals will also need to demonstrate behavioral competencies that enable teamwork, foster innovation and support collaboration to achieve business results. 
A plant pathologist's role in the discovery and development of disease control products

R. BOUNDS (1)

(1) Syngenta Crop Protection, Visalia, CA, U.S.A.

Phytopathology 105(Suppl. 4):S4.178

Plant pathologists in industry contribute to the discovery and development of new products. Closely working with chemists, key targets and assay systems are developed to quickly determine which of the thousands of compounds screened should be advanced for further evaluation. Laboratory experiments are initially required to assess new products while greenhouse and field studies are needed to promote products through the development pipeline and into the market. Industry plant pathologists utilize a wide range of skills in basic and applied plant pathology to develop new innovations into products that directly contribute to disease management. This presentation will describe specific roles and how to prepare for a career as an industry plant pathologist.
The role of private practitioners in providing research or support for industry

C. M. BECKER (1)

(1) BAAR Scientific LLC, Romulus, NY, U.S.A.

Phytopathology 105(Suppl. 4):S4.178

This session will discuss the opportunities available as Private Practitioners. There is no average Private Practitioner; but in general, they can be grouped into one of three categories. First, plant pathologists can become crop consultants, either as an individual, or as a team member of a much larger company. Second, individuals can conduct applied agricultural research. Applied research generally consists of either residue trials, where research is conducted under "good laboratory practices (GLP's)" or efficacy trials, following protocols generated by either the individual Private Practitioner, or by a product development company. The third category consists of unique opportunities supporting Industry. Individuals tend to fall into this last category later in ones career. Diverse skill sets and self motivation, are essential personal traits required for success. Daily activities include multitasking and networking. Most Private Practitioners tend to be attracted to the applied side of Plant Pathology. Plant Pathologists with either Masters Degrees or PhD can be equally successful as Private Practitioners.

\section{Engagement in Plant Pathology: You Can't Start Too Early}

\author{
Kids and plants: The Summer Science Camp for elementary school \\ students \\ C. SMART (1), S. Reiners (1) \\ (1) Cornell University, Geneva, NY, U.S.A. \\ Phytopathology 105(Suppl. 4):S4.178
}

To enhance K-12 science literacy, scientists at Cornell University's New York State Agricultural Experiment Station have partnered with the Geneva City School District in Geneva, NY. The goals of this program are to (i) engage elementary aged students in a hands-on, inquiry-based study of science; (ii) generate awareness of how food is grown and where it comes from; and (iii) increase student exposure to agricultural sciences and related careers. Beginning in the spring of their third-grade year, students are visited by Cornell faculty and learn about and plant seeds, they take a field trip to Cornell's Geneva campus (about 0.5 miles from their school), and the students plant a vegetable and flower garden at their school. During the summer, students have the opportunity to participate in a 5-week science camp run by school district faculty and scientists from Cornell. We have seen several positive outcomes from this program, including increased student knowledge, based on pre- and post-tests given during the Summer Science Camp; increased enrollment in local 4-H programs; and an increase in the proportion of students who pass the fourth-grade science test mandated by New York State. In addition, this program helps plant pathologists and other scientists from Cornell foster good relationships with, and increase their impact in, our local community.

PlantingScience: A mentoring program in plant sciences to capture the interest of middle and high school students

C. T. ADAMS (1)

(1) Botanical Society of America, St. Louis, MO, U.S.A.

Phytopathology 105(Suppl. 4):S4.178

PlantingScience is a Spore award-winning online mentoring program making a big impact on the way science, especially plant science, is taught in secondary schools. It stems from a National Academies challenge to societies to bring scientists into the classroom and improve students' scientific literacy. Since 2005, >800 scientists from the American Phytopathological Society, the Botanical Society of America and 12 other scientific societies have come together to inspire interest in plant science, mentoring over 16,000 students on student-generated science projects. Student teams appreciate the chance to answer their own questions scientifically and to have conversations with scientists who help them to work as scientists. Plant-based projects engage students with plants and expose the importance of plants to the world. Despite national efforts, scientific literacy, especially botanical literacy, is still in decline. Teachers report being more comfortable using animal examples over plant examples when teaching biological concepts. Only $60 \%$ of US high school biology teachers report having ever taken a botany course. By bringing societies of plant scientists together, we can expand PlantingScience into a new decade, reaching more students and teachers in our quest towards a common goal of widespread scientific and botanical literacy. Join us: help open the eyes of students and teachers around the world to the key importance of plant science for our future.

Magical mushrooms and mischievous molds - The gateway to a lifelong fascination with plant pathology

G. HUDLER (1)

(1) Cornell University, Ithaca, NY, U.S.A.

Phytopathology 105(Suppl. 4):S4.178

If I hadn't been required to take a course in Forest Pathology in 1969, I'm sure I'd be doing something else now. Most noteworthy in that critical 10 weeks of my life was that I learned I could put my new knowledge (and what I could learn via novel research thereafter) to immediate use to make peoples' lives better. Many APS members also have the genesis of their interest in plant pathology in a required course, and that factor shouldn't be overlooked. While launching Magical Mushrooms, Mischievous Molds at Cornell, I didn't plan to turn many students into plant pathologists but I did want to have impact comparable to that professor who had been so important to me earlier. With page after page from his playbook, I told stories - each with an intelligible beginning and without acronyms, I learned to use humor to advantage, and I aspired to have every student leave every class with some meaningful new nugget of wisdom. Today, not a month passes that I don't hear from former students that something they learned from me made a difference in their lives. About a dozen have changed paths to become plant scientists, and others elsewhere in the world who were inspired by the example we set have also found a latent passion and run with it. I'm surprised, I'm flattered, and I'd do it all over again exactly the same way if the chance arose because the results exceeded my wildest expectations.

Recruiting for the profession of plant pathology through internships D. M. GADOURY (1)

(1) Cornell University, Geneva, NY, U.S.A.

Phytopathology 105(Suppl. 4):S4.178

Applications to many graduate programs of plant pathology had declined substantially at many US institutions between 2000 and 2005. The systematic identification of the factors that were most influential in career choices of undergraduates revealed something that should have been quite obvious to professional plant pathologists: that work experience was the most common portal through which most enter plant pathology as a career, and that work experience remains today one of the most powerful means by which we can attract talented undergraduates to the study of plant pathology. The subsequent creation, promotion and expansion of Internship and REU (Research Experience for Undergraduates) programs by many departments was accompanied by an increase in applications and enrollments in graduate programs. These programs can be purpose-built to serve a need for research experience, and demonstrably function as highly effective and efficient means of attracting the best undergraduate talent to $\mathrm{MS}$ and $\mathrm{PhD}$ programs. The key components of a successful Internship/REU program, including funding, promotion, mentoring, content, motivation, and networking opportunities will be presented. 
Reflections on an undergraduate research experience: How I was hooked W. WELDON (1)

(1) Cornell University, Geneva, NY, U.S.A.

Phytopathology 105(Suppl. 4):S4.179

I was once a freshman Pre-med and Chemistry major at Butler University. With a BS in Biology, I am now headed for a PhD in Plant Pathology. Clearly, something hooked me into this obscure field. It began with a job at Butler, where I worked in a lab focused on a fungal plant pathogen. Thus, I was aware of the field's existence when I applied for a summer internship at Cornell, but I was not yet thinking of plant pathology as a career. That all changed during the internship, not just for me, but for many of my fellow interns. I learned of the program through an e-mail sent to our Biology department, and was directed via an internet search to the application website. "Google" was the means by which most of my peers found internships. My internship integrated field and laboratory research, and a graduate level field course in plant pathology. It opened my eyes to the importance of plant pathology to agriculture and the world. It also revealed an opportunity for one person to make an immediate and positive impact. Interactions with growers through the field course connected the research to implementation. It was as important as the research, and was the major hook for me and many of my peers. The internship was also my first real opportunity to see graduate student life from the inside, and made me confident that I'd made the right choice in applying to a graduate program in plant pathology.

\section{Participatory Plant Disease Research: Advancing Sustainable Food Production Through Farmer- Researcher Partnerships}

\section{Participatory sweetpotato breeding and germplasm evaluation for resistance to viral and fungal diseases}

R. O. MWANGA (1), R. W. Gibson (2), G. N. Ssemakula (3), C. G. Yencho (4) (1) International Potato Center, Kampala, Uganda; (2) Natural Resources Institute, Kent, United Kingdom; (3) National Agricultural Research Organization (NARO), Kampala, Uganda; (4) North Carolina State University, Raleigh, NC, U.S.A.

Phytopathology 105(Suppl. 4):S4.179

Sweetpotato is important for calories and provitamin A in developing economies. Propagated vegetatively, sweetpotato can accumulate pathogens, resulting in reduced yield losses ( 50 to $>90 \%$ ), prompting breeding for increased disease resistance. Scientists and farmers in Uganda identified preferred cultivars through participatory varietal selection, and new clones from seedling populations through a participatory plant breeding (PPB) approach. Farmers identified 51 attributes of their landraces or released varieties and used 21 criteria to select clones from seedling populations. Scientists had a shorter list of attributes; some cultivar attributes important to farmers were overlooked by scientists. The process of PPB in farmers' fields amongst a scientist-derived seedling population led to the eventual official release of the sweetpotato cultivar, NASPOT 11 (Tomulabula), in 2010 in Uganda. NASPOT 11 had high Alternaria blight resistance in field trials under high inoculum pressure at Kachwekano. Sweetpotato virus disease (SPVD) resistance and tolerance were confirmed by scientists in quantitative reverse transcription polymerase chain reaction assays. NASPOT 11 is also high yielding, with high dry matter content $(>30 \%)$ and is now widely grown in Uganda.

\section{Participatory research with tree crop farmers in the Pacific}

D. I. GUEST (1), R. Daniel (1)

(1) The University of Sydney, Eveleigh, Australia

Phytopathology 105(Suppl. 4):S4.179

European colonists introduced plantation crops into the Pacific and developed research and extension services with strong linkages between plantation owners, managers, extension agents and researchers. With the collapse of plantation agriculture these services became increasingly underfunded, irrelevant and ineffective for smallholder-based farming communities. While farmers are observant and innovative, they are also are risk-averse because they lack the skills to critically evaluate the benefits of technological change, or their capability is limited by poor health, education, custom, land tenure or finance. Farmer participatory research engages stakeholders at the beginning of the research and development cycle, focuses research questions and extension approaches, creates healthy and robust partnerships based on trust and "learning by doing", and engages farmers as advocates. The adoption of new technologies is improved if farmers are presented with graded management options demonstrated by active participants, rather than passively promoted and inflexible recommendations. We have successfully applied the participatory approach to assist cacao, pineapple, citrus, tomato, potato, rubber, black pepper, durian and jackfruit farmers in several countries in Southeast Asia and the Pacific. We are now exploring trans-disciplinary approaches to simultaneously address agriculture, health and nutrition constraints in smallholder farming communities.

Participatory plant breeding and the effects of on-farm conservation and selection on diversity and adaptation

J. DAWSON (1)

(1) University of Wisconsin-Madison, Madison, WI, U.S.A.

Phytopathology 105(Suppl. 4):S4.179
Participatory plant breeding was developed to respond to the needs of lowinput systems by drawing on farmer knowledge of these systems. Participatory research is also increasingly used in organic agriculture. Participation differs from on-farm trialing in that farmers drive research objectives, and may have different goals than researchers initially expect. Farmers have developed strategies for disease management that include diversity in their crops, and carry a focus on diversity into participatory breeding efforts. Projects on wheat in France and tomatoes in Wisconsin will be discussed with respect to disease management. Farmers involved in the participatory wheat program have relied on diverse wheat varieties and mixtures because they observe better performance in their fields. Plant health is a major selection focus, even though this is not measured as resistance to particular diseases. Farmers focused on plant health as a trait important to grain and baking quality and were not concerned with complete resistance. Similarly, organic tomato growers in Wisconsin are focused on flavor and quality more than complete disease resistance. Often resistant varieties are associated with poor flavor, so farmers do not use these varieties even if they are available. The goal of the project is to improve disease tolerance in high quality varieties, by drawing on diverse germplasm and by involving chefs and consumers in the evaluation process in addition to farmers.

\section{A framework for optimizing participatory research}

K. GARRETT (1)

(1) University of Florida, Gainesville, FL, U.S.A.

Phytopathology 105(Suppl. 4):S4.179

Participatory research holds the potential for improved system outcomes, such as resistant varieties and other IPM strategies better matched to stakeholder needs. Including a participatory research component generally requires additional investment, so it is useful to know under what circumstances the investment is rewarded and how participatory research can be optimized. Impact Network Analysis offers a platform for evaluating optimization strategies for participatory research. An "impact network" is the linked socioeconomic and biophysical networks through which new technologies can impact system outcomes. An "Impact Network Analysis" (INA) is an evaluation of how impact networks function in a particular setting, such as participatory research to improve disease management, and where the control points for improvement are. For example, in the context of seed degeneration due to the accumulation of pathogens in vegetatively-propagated crops, INA can be used to evaluate what system-wide benefit is anticipated if there is a greater degree of participation in research for on-farm integrated seed management. Key factors include the degree of farm heterogeneity, the effects of which can be better understood through wider participation, and the degree of mismatch between the perceived priorities of farmers and scientists. Optimization strategies can be devised to efficiently address these factors.

Improving the health and productivity of organic potato crops through participatory research

R. K. GENGER (1), D. I. Rouse (1), R. Groves (1), A. O. Charkowski (1)

(1) University of Wisconsin-Madison, Madison, WI, U.S.A.

Phytopathology 105(Suppl. 4):S4.179

Seed potatoes can carry pathogens that significantly affect crop productivity. Management of these pathogens includes a certification process which rejects seed lots above a strict pathogen incidence threshold. Organic farmers, who are required to plant organically produced seed where available, face challenges in obtaining certified seed potatoes for desired varieties. We conducted researcher-managed trials on organic farms which demonstrated the feasibility of organic production of seed potatoes. Through this process we realized the importance of farmer partnerships in setting research directions and improving adoption of research-based recommendations. Through consultations with growers, we found that growers placed a high priority on 
selection of varieties suited to organic management. We initiated on-farm variety selection trials, and transitioned from researcher management to farmer management of trials. As part of this transition, we adopted a "motherbaby" trial design in which replicated variety trials were planted in researchermanaged trials, and single replicates of variety subsets were planted in farmer- managed trials at organic farms throughout the Upper Midwest. Through this research we have identified characteristics of potato varieties that thrive under organic management, breeding goals for organic potato production, and constraints due to farm environment. Coming full circle, we are initiating farmer-led trials of organic seed potato production.

\section{Plant Pathologists of the Future: Showcasing the Top Graduate Students from APS Division Meetings}

Caribbean Division - An approach for screening Musa accessions for resistance to virulent Mycosphaerella fijiensis isolates

L. GANAN (1), E. Alvarez (1)

(1) CIAT, Palmira, Colombia

Phytopathology 105(Suppl. 4):S4.180

Certain Musa cultivars and hybrids are resistant to black leaf streak disease (BLSD), caused by the fungus Mycosphaerella fijiensis. Because this pathogen is highly diverse genetically, it can attack newly introduced Musa accessions, including resistant ones. The virulence of six M. fijiensis isolates was evaluated in a susceptible cultivar, plants of which were inoculated by brushing weighed fragmented mycelium onto specific areas of abaxial leaf surfaces. The same assay and the same six M. fijiensis isolates were also used to determine the resistance of six Musa hybrids and 10 cultivars under greenhouse conditions. Disease severity (DS) was measured, using digital image analysis software. A qualitative scale was used to determine severity of infection, allowing calculation of incubation period and time of symptom development. Results demonstrated differences in virulence among the isolates, with two showing mild virulence $(<20 \%)$. Symptoms of BLSD were observed in all accessions, but with significant differences in DS. Two hybrids, one cultivar, and the resistant control, inoculated with the most virulent isolates, nevertheless had the lowest mean values for DS. Categorical data and correspondence analyses clustered the Musa accession $x$ M. fijiensis isolate interactions into three main groups, according to resistance levels. This method is quick, inexpensive, and easy for screening partially resistant Musa accessions against isolates differing in virulence.

North Central Division - Overexpression of a modified eIF4E gene confers broad-spectrum resistance to Potato virus $Y$ and is dominantly inherited in various potato varieties

E. ARCIBAL (1), M. Jahn (1), J. Jiang (1), A. Rakotondrafara (1)

(1) University of Wisconsin, Madison, WI, U.S.A.

Phytopathology 105(Suppl. 4):S4.180

Potato virus $Y$ (PVY) has reemerged as an important threat to the potato industry in the United States, causing an upwards of $50-80 \%$ yield loss in severely infected fields. Reemergence is partially due to the popularity of cultivars that do not exhibit clear symptoms upon infection, such as Russet Norkotah, leading to high PVY accumulation in fields and the generation of novel recombinant strains. Although genetic resistance is the most effective management strategy, tetraploid breeding is difficult, and ideal traits can be lost during the introgression of disease resistance genes. Recently, PVY resistance has been engineered by overexpressing a modified native potato gene (eIF4E), which successfully conferred resistance to PVY in the susceptible cultivar, Russet Burbank. Key mutations in eIF4E confer resistance by rendering it unusable to the invading virus, however compensatory resistance breaking viral mutations restore an interaction and thus susceptibility. We have expanded this technology to highly susceptible Russet Norkotah and Atlantic cultivars. Through ELISA testing, we have identified particular lines of each cultivar that display broad-spectrum resistance to three PVY strains in local and systemic leaf and tuber tissues. We have also determined the overexpressed modified eIF4E gene, which in native systems is recessive in nature, is dominantly inherited.

Northeastern Division - Establishment of soil and tissue potassium sufficiency ranges for control of anthracnose disease on annual bluegrass turf C. J. SCHMID (1), J. A. Murphy (1), B. B. Clarke (1)

(1) Rutgers University, New Brunswick, NJ, U.S.A.

Phytopathology 105(Suppl. 4):S4.180

Potassium is an important soil nutrient that strongly influences the tolerance of turfgrasses to environmental stresses. Anthracnose, caused by Colletotrichum cereale, is a destructive fungal disease of annual bluegrass (ABG; Poа апnиа) turf that is exacerbated by nutrient deficiencies such as $\mathrm{N}$ and K. A 3-yr field study was initiated in 2012 to evaluate the response of $\mathrm{ABG}$ turf to a range of soil test $\mathrm{K}$ (STK) levels and determine critical soil and tissue $\mathrm{K}$ for the suppression of anthracnose. Treatments were arranged as a $2 \times$
4 factorial with four replications. Potassium chloride and potassium sulfate were applied at rates of $0,66,131$, and $262 \mathrm{~kg} \mathrm{~K} \mathrm{ha}^{-1} \mathrm{yr}^{-1}$. Potassium nitrate and potassium carbonate were also included at the $262 \mathrm{~kg} \mathrm{~K} \mathrm{ha}^{-1} \mathrm{yr}^{-1}$ rate. Anthracnose severity was positively correlated to both STK and tissue K content and provided clear critical values for disease suppression using the CateNelson model; 43, 49, and $45 \mathrm{mg} \mathrm{kg}^{-1}$ STK in 2012, 2013, and 2014, respectively, and 19.6 to $19.8 \mathrm{~g} \mathrm{~kg}^{-1}$ tissue $\mathrm{K}$ in 2012 and 2013, respectively. Nonlinear regression analysis of tissue K and STK values indicates that STK levels above $100 \mathrm{mg} \mathrm{kg}^{-1}$ did not increase tissue $\mathrm{K}$ content; therefore, there may be no benefit to increasing STK above this level. Few differences were seen between $\mathrm{K}$ sources in 2012 and 2013; however, in $2014 \mathrm{KCl}\left(262 \mathrm{~kg} \mathrm{~K} \mathrm{ha}^{-1} \mathrm{yr}^{-1}\right)$ produced the lowest suppression in disease severity of the four $\mathrm{K}$ sources.

Pacific Division - Endophytic bacteria as biological control for the management of Fusarium euwallaceae - a symbiotic fungus of the Polyphagous Shot Hole Borer

F. NA (1), D. H. Wang (1), M. Twizeyimana (1), J. S. Mayorquin (1), K. Sugino (1), J. D. Carrillo (1), A. Eskalen (1)

(1) University of California, Riverside, CA, U.S.A.

Phytopathology 105(Suppl. 4):S4.180

The ambrosia beetle Polyphagous Shot Hole Borer (Euwallacea sp.) and the fungal pathogen Fusarium euwallaceae are an invasive vector-pathogen complex that is threatening the avocado industry and the native tree species of Southern California. Current lack of effective management strategies against the beetle or the fungus has allowed the infestation to spread rapidly throughout Southern California, including several commercial avocado groves located in Los Angeles and San Diego Counties. In this study, we examined the potential use of biological control treatments for the management of $F$. euwallaceae. A collection of endophytic fungi and bacteria was obtained from the xylem of healthy avocado (Persea americana) and California sycamore (Platanus racemosa) within beetle-infested areas in order to screen for endophytes that are able to inhibit $F$. euwallaceae. These endophytes were cocultured with $F$. euwallaceae on culture media and were monitored for inhibition. Thirteen isolates of bacteria from California sycamore and two isolates of bacteria from avocado were found to be capable of inhibiting the fungus. The endophytes were found to inhibit $F$. euwallaceae in vitro with varying levels of efficacy, and the highest performing isolates were chosen for further studies in planta. Results from the in vitro study and preliminary data from the in planta study show promise of environmentally safe biocontrol treatments to protect woody plants of Southern California

Potomac Division - Evaluation of fungicides for efficacy against pod rot of lima bean caused by Phytophthora capsici

A. A. KNESS (1), G. C. Johnson (2), N. M. Donofrio (1), T. A. Evans (1), E. G. Ernest (2), K. L. Everts (3), N. F. Gregory (1), H. N. Baker (2)

(1) University of Delaware, Newark, DE, U.S.A.; (2) University of Delaware, Georgetown, DE, U.S.A.; (3) University of Maryland, Salisbury, MD, U.S.A. Phytopathology 105(Suppl. 4):S4.180

Pod rot caused by Phytophthora capsici is a devastating disease of lima bean (Phaseolus lunatus) on the Delmarva Peninsula. Management of pod rot is often limited to fungicides. However, only two fungicides, mefenoxam (Ridomil Gold), registered since 1992, and more recently, cyazofamid (Ranman) are registered for the management of pod rot. Because growers have relied on mefenoxam for management, resistant populations of $P$. capsici have developed. Ten fungicides, in addition to Ridomil and Ranman, were tested for their efficacy in controlling pod rot of lima bean. Two separate field trials were conducted at the University of Delaware's Carvel Research and Education Center in Georgetown, Delaware in 2014. The first and second field locations had moderate and heavy disease pressure, respectively. Results indicate that all tested fungicides significantly reduced disease incidence when compared to the water control treatment in both trials. Applications of Ridomil, Ranman, Omega, and Zorvec consistently achieved in the greatest reduction of pod rot. There was no significant difference in yield among treatments in the first field location (moderate disease pressure). However, the control plots in the second field location (heavy disease pressure) yielded significantly less, with potential yield loss over $86 \%$. These trials indicate that there are additional fungicides with efficacy against $P$. capsici on lima bean which merits further research to support their labelling. 
Southern Division - Pathogenicity evaluations of novel ectotrophic rootinfecting fungi on ultradwarf bermudagrass

P. L. VINES (1), M. Tomaso-Peterson (1), T. Allen (1)

(1) Mississippi State University, Mississippi State, MS, U.S.A.

Phytopathology 105(Suppl. 4):S4.181

Ultradwarf bermudagrass root systems affected by summer decline are typically diminutive in size, brown to black in color, and are frequently colonized with dark runner hyphae, growth cessation structures, and simple and lobed hyphopodia, which are characteristic signs of ectotrophic rootinfecting (ERI) fungi. Research at Mississippi State University led to the identification of six novel fungal species and two previously recognized species from colonized roots. The objective of this study was to screen ERI fungal species for pathogenicity on 'Champion' and 'MiniVerde' ultradwarf bermudagrasses. Representative isolates from each of the eight fungal species were selected and grown on potato dextrose agar (PDA) under 24 hour fluorescent light for 14 days. The experiment was conducted in a randomized complete block split-plot design with three replications. Ultradwarf bermudagrass cultivars $(\mathrm{n}=2)$ were whole plots and fungal isolates $(\mathrm{n}=10)$ were split-plots. In vivo inoculations were performed in $7.6 \mathrm{~cm}$ diameter pots and placed in light- and temperature-controlled growth chambers for eight weeks. Pathogenicity of root systems was assessed via pixel color analyses in WinRhizo and Koch's postulates were confirmed by reisolation of the fungus from roots within each pot. All ERI fungi were pathogenic to both ultradwarf bermudagrass cultivars; however, severity levels varied among species. The greatest root disease severity was incited by two novel species.

\section{Schroth Faces of the Future: Nematology}

Nematode management without methyl bromide in California grape production

J. A. CABRERA (1)

(1) Bayer CropScience, Fresno, CA, U.S.A.

Phytopathology 105(Suppl. 4):S4.181

The objective of this research was to identify nematode management strategies without methyl bromide in California grape production. In the first field study, the rootstock Freedom demonstrated to be a more important tool than 1,3dichloropropene and chloropicrin $(1,3-\mathrm{D}+\mathrm{Cp})$ for Meloidogyne spp. management, however, the contrary occurred against $T$. semipenetrans. This fumigant treatment was more important than the root-stock in both nematode genera when the 1103P rootstock was used. In another study, reduced 1,3-D+Cp rates $(3 / 4,1 / 2$, and $1 / 4)$ under low permeable films provided adequate control of $M$. incognita and T. semipenetrans. In a third field study, post-planting spot-fumigation with reduced dimethyl disulfide rates provided high control Meloidogyne spp., T. semipenetrans, and Criconemella xenoplax in established Thompson Seedless vines grown on their own roots. Another study demonstrated that spirotetramat, a non-fumigant systemic compound, applied in spring and fall as a post-planting treatment reduced a variety of plant parasitic nematode populations. Spirotetramat applied twice a year at $6.25 \mathrm{onz} /$ acre increased grape yield compared to the untreated control in a Zinfandel vineyard. The insights of these studies and the multidiscipline collaborative research required to conduct these investigations will be presented.

\section{Exploration of nematode-secreted CLE Effectors for developing tools to} accelerate nematode resistance breeding in crop plants

S. CHEN (1), X. Wang (2)

(1) Plant Pathology and Plant-Microbe Biology Section, School of Integrative Plant Science, Cornell University, Ithaca, NY, U.S.A.; (2) USDA-ARS, Robert W. Holley Center for Agriculture and Health, Ithaca, NY, U.S.A. Phytopathology 105(Suppl. 4):S4.181

Like other biotrophic pathogens, plant-parasitic nematodes secrete effector proteins into host plant cells to facilitate successful infection. CLE effectors, identified in cyst nematodes including the regulated potato cyst nematodes (PCN; Globodera rostochiensis and G. pallida), can mimic plant CLE peptide hormones to modulate plant developmental pathways, thereby promoting nematode parasitism. Transgenic potato plants expressing dsRNA targeting the PCN CLE gene showed increased resistance to PCN infection, suggesting that plant-delivered RNAi represents a valuable means for generating novel nematode resistance in crop plants. We have further identified a receptor StCLV2 in potato found to interact with PCN-secreted CLE peptides. Significantly, transgenic potato plants with reduced StCLV2 expression showed enhanced resistance to the two PCN species, indicating that interference of the CLV2-mediated signaling pathway may result in broadspectrum nematode resistance in potato. Experiments are underway to identify nonfunctional receptor alleles that fail to perceive PCN-secreted CLE peptides through screening of wild Solanum species. Due to the critical role of nematode CLE mediated signaling in parasitism, we expect that manipulating CLE receptors in the host, such as through genome editing, offers a powerful method for accelerated nematode resistance breeding in crop plants.

Assessment of fluopyram in the management of nematodes in soybean and cotton

T. R. FASKE (1)

(1) University of Arkansas, Lonoke, AR, U.S.A.

Phytopathology 105(Suppl. 4):S4.181
Management of the southern root-knot nematode, Meloidogyne incognita, and the reniform nematode, Rotylenchulus reniformis, is of critical importance to soybean and cotton producers in the southern United States. Current management strategies continue to rely on nematicides because of the limited availability of resistant cultivars with high yield potential. Currently, fluopyram, an SDHI fungicide is being evaluated as a seed and in-furrow treatment for suppression of nematodes in a few row crops. Based on an assay of nematode motility $M$. incognita and $R$. reniformis are sensitive to fluopyram. Their respective $\mathrm{EC}_{50}$ values are similar to that of abamectin; however recovery was observed for both species. In field trials, fluopyram applied as an in-furrow application at planting was numerically more effective at suppressing early season nematode infection in cotton and soybean compared to fluopyram applied as a seed treatment. Further, early season nematode suppression was similar among commercially available nematicides seed treatment and fluopyram. Based on a lab assay, the majority of the fluopyram remains on the seed coat rather than being transferred to the developing radicle. Thus, the limited early season nematode suppression suggest that only a small portion of the fluopyram applied to the seed was transferred to the developing root system. Further studies are underway to determine how fluopyram may benefit soybean and cotton producers.

Exploiting the host cell cycle machinery to control the root-knot nematode feeding site development

P. VIEIRA (1)

(1) Dept. of Plant Pathology, Physiology, and Weed Science, Virginia Tech and Floral and Nursery Plants Research Unit, USDA, Beltsville, MD, U.S.A.

Phytopathology 105(Suppl. 4):S4.181

Root-knot nematodes are considered one of the most specialized and harmful plant-parasitic nematodes. The capacity of manipulating the host cell cycle machinery is a fundamental process for the successful reproduction of these plant pathogens. Development of the giant cells within the nematode feeding sites induced by root-knot nematodes involves the activation of cell cycle programs like acytokinetic mitoses and endoreduplication. Understanding the molecular mechanism of how root-knot nematodes maneuvers the host cell cycle can bring new opportunities to exploit diverse and novel forms of plant resistance. A typical cell cycle encompasses four sequential ordered phases (G1, S, G2, and M), distinguishing the temporal replication of the cellular genetic material from the segregation of duplicated chromosomes into twodaughter cells. In plants, the regulation of the cell cycle is driven by the activation of cyclin-dependent kinases (CDKs) through multiple transcriptional and post-translational mechanisms that control their activity. In this scenario, plant Kip-Related Proteins (ICK/KRP inhibitors) are regulators of the CDKs, and modulating ICK/KRP activity can be envisaged as blocking nematode feeding site development. Here we investigated the influence of this gene family during plant-nematode interaction, revealing that ICK/KRP members control nematode gall development in Arabidopsis. Our results show that by intensifying CDK inhibition through overexpression of ICK/KRP family members, dramatically affects nematode feeding site development, and consequently compromising the nematode's life cycle. Herein we present data related with four $I C K / K R P$ genes exerting different functions during feeding site development. Thus, control of root-knot nematodes by modulating cell cycle-directed pathways through the enhancement of KRP protein levels may serve as an attractive strategy to limit damage caused by these plant parasites. 